\title{
PP2A-Cdc55 phosphatase regulates actomyosin ring contraction and septum formation during cytokinesis
}

\author{
Yolanda Moyano-Rodríguez ${ }^{1}$ - David Vaquero ${ }^{1,2}$ - Odena Vilalta-Castany ${ }^{1} \cdot$ Magdalena Foltman $^{3,4}$. \\ Alberto Sanchez-Diaz ${ }^{3,4} \cdot$ Ethel Queralt ${ }^{1,2}$ (D)
}

Received: 1 September 2021 / Revised: 11 February 2022 / Accepted: 13 February 2022 / Published online: 1 March 2022

(c) The Author(s) 2022

\begin{abstract}
Eukaryotic cells divide and separate all their components after chromosome segregation by a process called cytokinesis to complete cell division. Cytokinesis is highly regulated by the recruitment of the components to the division site and through post-translational modifications such as phosphorylations. The budding yeast mitotic kinases Cdc28-Clb2, Cdc5, and Dbf2Mob1 phosphorylate several cytokinetic proteins contributing to the regulation of cytokinesis. The PP2A-Cdc55 phosphatase regulates mitosis counteracting Cdk1- and Cdc5-dependent phosphorylation. This prompted us to propose that PP2A-Cdc55 could also be counteracting the mitotic kinases during cytokinesis. Here we show that in the absence of Cdc55, AMR contraction and the primary septum formation occur asymmetrically to one side of the bud neck supporting a role for PP2A-Cdc55 in cytokinesis regulation. In addition, by in vivo and in vitro assays, we show that PP2A-Cdc55 dephosphorylates the chitin synthase II (Chs2 in budding yeast) a component of the Ingression Progression Complexes (IPCs) involved in cytokinesis. Interestingly, the non-phosphorylable version of Chs2 rescues the asymmetric AMR contraction and the defective septa formation observed in $c d c 55 \Delta$ mutant cells. Therefore, timely dephosphorylation of the Chs 2 by PP2A-Cdc55 is crucial for proper actomyosin ring contraction. These findings reveal a new mechanism of cytokinesis regulation by the PP2A-Cdc55 phosphatase and extend our knowledge of the involvement of multiple phosphatases during cytokinesis.
\end{abstract}

Keywords Cell Cycle $\cdot$ Cytokinesis · PP2A-Cdc55 - Ingression progression complexes (IPCs) - AMR contraction · Hof 1 . Cyk3 $\cdot$ Myo 1

\section{Introduction}

Cytokinesis is the final event of the cell cycle and mediates the physical separation of mother and daughter cells. It is a highly ordered and regulated process that is conserved among eukaryotes. Cytokinesis must be spatially and temporally coordinated with sister chromatids segregation to

Ethel Queralt

equeralt@ibv.csic.es

1 Cell Cycle Group, Institut d'Investigació Biomèdica de Bellvitge (IDIBELL), Av. Gran Via de L'Hospitalet 199-203, L'Hospitalet de Llobregat, Barcelona, Spain

2 Instituto de Biomedicina de Valencia (IBV-CSIC), C/ Jaume Roig 11, Valencia, Spain

3 Instituto de Biomedicina y Biotecnología de Cantabria, Universidad de Cantabria, CSIC, Santander, Spain

4 Departamento de Biología Molecular, Facultad de Medicina, Universidad de Cantabria, Santander, Spain avoid problems in chromosome segregation -failures can lead to aneuploidies and are associated with tumorigenesis [1]. Detailed mechanistic studies are important to understand cytokinesis relevance in normal cellular functions as well as its impact on human diseases.

In fungi and animal cells, the cytokinetic machinery comprises two major elements: septin and contractile actomyosin rings. In Saccharomyces cerevisiae, the process takes place at the division site, a narrow region linking mother and daughter cells known as the bud neck. At the end of G1, the Cdc42 GTPase polarizes actin cables and patches towards the new bud site, and the septin ring is assembled [2,3]. The septin ring is reorganized later in $\mathrm{S}$ phase and becomes an hourglass-like structure [4] that will split into two rings in anaphase [5-7]. Septins serve as an anchor for various cytokinesis-related proteins including the type II myosin heavy chain, Myo1 [8]. Myo1, together with actin filaments and the essential and regulatory myosin light chains Mlc1 and Mlc2, shape the actomyosin ring (AMR) [5, 8-10]. The 
AMR leads to furrow ingression through its contraction and constriction [11, 12].

Cytokinetic regulatory proteins such as Iqg1, Hof1, Inn1 and Cyk3 are recruited at the AMR [6, 13-15], which mediate the activation of the chitin synthase II, Chs2 [6, 16-18]. Chs2 synthesizes the primary septum (PS), concomitantly with AMR constriction [19, 20], and drives the second part of its contraction [21]. These proteins are part of the Ingression Progression Complexes (IPCs) [17, 22], which coordinates primary septum formation, actomyosin ring contraction and ingression of the plasma membrane at the division site [16, 17, 23-26].

Once the PS has been synthesized, the two secondary septa (SS) will be formed by Chs3, glucan synthases (Fks1) and mannosyltransferases on both sides of the PS [20,27, 28]. Finally, cytokinesis is completed when the daughter cell synthesizes hydrolases and chitinases to hydrolyze the remaining cell wall structures in between SS [29].

The timing of cytokinesis must be tightly regulated to ensure it only happens when anaphase is completed. Anaphase is regulated by two pathways: FEAR (CdcFourteen Early Anaphase Release) and MEN (Mitosis Exit Network). Both are coordinated to promote the activation of the $\mathrm{Cdc} 14$ phosphatase [30-33]. Cdc14 is responsible for Cdk1 (Cdc28 in budding yeast) inactivation and the dephosphorylation of Cdk1 targets during mitosis [34]. Several MEN kinases have been found to be involved in cytokinesis [35]. Pololike kinase, $\mathrm{Cdc} 5$ regulates AMR formation and membrane ingression [36, 37]. Dbf2, the downstream MEN kinase, phosphorylates Hof 1 promoting its re-localization from the septin ring to the AMR [7, 36]. Cdk1-Clb2 phosphorylates Iqg1 (limiting the actin recruitment at the division site) [38, 39] and Chs2 (promoting its retention at the endoplasmic reticulum (ER)) [40-42]. Cdk1 also inhibits Iqg1 and Inn1 localization at the division site, and Inn1 interaction with IPCs [38, 43, 44]. Later on, MEN and Cdc14 phosphatase initiate cytokinesis by counteracting Cdk1 phosphorylation in budding yeast $[39,41,44,45]$. However, the inactivation of Cdk1-Clb2 activity during late anaphase is not sufficient to trigger cytokinesis $[41,46]$, it is also necessary the Cdc14-dependent dephosphorylation of Iqg1, Inn1 and Chs2 for cytokinesis completion [39, 41, 44, 45]. Chs2 translocates to the division site upon Chs 2 dephosphorylation by Cdc14 [41, 47].

Recent work demonstrates that multiple phosphatases shape the phosphoproteome during mitotic exit [48, 49], pointing out the contribution of other phosphatases such as PP2A-Rts1 and PP2A-Cdc55 [48]. These observations suggest that PP2A phosphatases could also be required for cytokinesis. Here, we propose that PP2A-Cdc55 regulates cytokinesis through the dephosphorylation of the IPC protein, Chs2. We have found that the PP2A-Cdc55 participates in the regulation of the phosphorylation state of Chs 2 and dephosphorylates Chs 2 in vivo and in vitro. Primary septum formation and actomyosin ring contraction are asymmetric in the absence of PP2A-Cdc55, supporting a role for PP2A$\mathrm{Cdc55}$ in cytokinesis regulation. Interestingly, the non-phosphorylable version of Chs2, chs2-S133A rescues the asymmetric AMR contraction and the defective septa formation in $c d c 55 \Delta$ mutant cells. The phospho-mimetic $c h s 2-S 133 E$ promotes a longer Hof 1 contraction time in wild-type cells, similarly to the absence of Cdc55, suggesting that hyperphosphorylation of Chs2 alters Hof1 residence time at the division site. In conclusion, PP2A-Cdc55 regulates AMR contraction and PS formation via the dephosphorylation of Chs2 during cytokinesis.

\section{Results}

\section{Defective septum formation and AMR contraction in the absence of Cdc55}

It was described that PP2A-Cdc55 is localized at the division site during cytokinesis [50]. However, neither a role for PP2A-Cdc55 during cytokinesis was demonstrated nor the molecular mechanism by which PP2A-Cdc55 could regulate cytokinesis. This prompted us to study the cytokinesis phenotypes of the $c d c 55 \Delta$ mutant cells.

Septins act as scaffold platforms for many proteins and impose a diffusion barrier for regulating cell polarity, cell remodeling and cytokinesis [51]. Septins localization and organization are highly dynamic through the cell cycle [52, 53]. We wondered whether septin structures were defective in the absence of Cdc55. Septins were visualized in situ by immunofluorescence staining of Cdc11 and Shs1-HA in asynchronous cells. The septin structures (septin rings, collar and double rings) were indistinguishable between $c d c 55 \Delta$ and wild-type cells (Fig. S1), suggesting that septin dynamics might not be greatly affected by the absence of Cdc55.

PP2A-Cdc55 regulates bud morphology through actin polarization and cell-wall synthesis [54]. Actin cytoskeleton polarization at the site of bud emergence is triggered at the Start by the kinase activities of Cln1,2-Cdc28. Upon Clb2Cdc28 kinase inactivation at the end of mitosis, the actin cytoskeleton is directed to the neck for the formation of the AMR $[9,39]$. We envisage the possibility that PP2A-Cdc55 influences also the actin cytoskeleton during cytokinesis. To examine this possibility, actin filaments were stained with rhodamine-labelled phalloidin in cells progressing through mitosis and cytokinesis in $c d c 55 \Delta$ cells. Actin signal was found to be depolarized in metaphase-arrested cells and localized at the bud neck in anaphase-cytokinesis in wildtype and $c d c 55 \Delta$ cells (Fig. S2a). However, in a subpopulation of $c d c 55 \Delta$ cells, actin polarization at the new bud was observed before cytokinesis had been completed (Fig. S2b). 
We observed actin signals simultaneously at the division site during cytokinesis and at the new bud site in $12.5 \%$ of $c d c 55 \Delta$ mutant cells, whereas there was no premature actin re-polarization at the new bud site in wild-type cells (Fig. $\mathrm{S} 2 \mathrm{~b})$. The premature actin localization indicates that actin re-polarization of the next cell cycle occurs before cell division in a fraction of $c d c 55 \Delta$ cells. Therefore, PP2A-Cdc55 could act to prevent actin re-polarization until cytokinesis is completed.

Cytokinesis in budding yeast is accomplished by the concerted action of the actomyosin contractile ring (AMR) and the septum formation. We investigated how these two processes occur in the absence of Cdc55. First, to investigate whether the actomyosin contractile ring is functional, we analyzed the localization of the Myo1-tdTomato fusion protein in cells progressing through mitosis and cytokinesis after synchronous release from the metaphase arrest by Cdc20 depletion. It has been described that Myo1 localizes to the division site immediately after budding. Accordingly, in metaphase-arrested cells Myo1-tdTomato was localized at the bud neck in control cells. Similarly, Myo1-tdTomato was also detected at the bud neck during metaphase in $c d c 55 \Delta$ mutant cells. In anaphase, the Myo1 signal is reduced, reflecting the contraction of the AMR, until the signal becomes a single dot and finally disappears (Fig. 1a). The dynamics of AMR contraction were similar in the two strains, but we observed that AMR contraction was asymmetric with respect to the centripetal axis in $86 \%(N=69)$ of $c d c 55 \Delta$ cells (Fig. 1b). To check whether the asymmetric Myo1 signal is not due to an adaptive mechanism of the $c d c 55 \Delta$ deletion mutant, we investigated the Myo1 contraction after inducing the $\mathrm{Cdc} 55$ degradation during metaphase using an auxin-degradation system [55]. Upon Cdc55 degradation, Myo1 contraction was also mostly asymmetric (86\% of cells) (Fig. 1c). The results indicate that the lack of PP2A-Cdc55 activity promotes the asymmetric contraction of Myo1.

We next examined whether Myo1 asymmetry could also be detected in the inactive version of Cdc55 (cdc55-ED). We synchronized cells at the metaphase-anaphase transition by Cdc20 depletion and analyzed the contraction of the Myo1tdTomato. We observed that $65 \%$ of $c d c 55-E D$ mutant cells showed an asymmetric Myo1-tdTomato signal upon contraction (Fig. 1c). This result indicates that, similar to the absence of Cdc55, the non-functional Cdc55 results in the alteration of AMR contraction. Overall, we conclude that Myo1 recruitment and time of localization at the division site are not altered in the absence of Cdc55, although AMR contraction is defective in the absence of PP2A-Cdc55 activity. This asymmetric localization has been reported before in some IPCs mutants [26] and suggests that PP2A-Cdc55 is required for efficient cytokinesis.
To assess whether the asymmetric AMR contraction phenotype was not affected by the synchronization method, we performed the assay synchronizing cells in G1 by alpha factor in absence of Cdc55. cdc55 $\Delta$ cells enter mitosis with a delay due to compromised Cdk1 activity because of inhibitory Cdc28-Y19 phosphorylation [56]. To correct for this delay, we introduced the $c d c 28 \_Y 19 F$ allele, which is refractory to Cdk1 inhibition. The $c d c 55 \Delta$ cells containing $c d c 28 \_Y 19 F$ progressed normally through the cell cycle [57]. Again, we observed that Myo1-tdTomato constriction was asymmetric in $80 \%$ of the $c d c 55 \Delta c d c 28 \_Y 19 F$ cell population (Fig. S3). Therefore, the asymmetric Myo1 signal in the absence of Cdc55 was observed independently of the synchronization method used.

To study septum formation, chitin deposition at the division site was analyzed by in vivo staining with calcofluor white and measured the fluorescence intensity of the incorporated calcofluor on living cells containing Myo1-tdTomato as a control for cytokinesis progression. We arrested cells at metaphase by Cdc20 depletion, released them into mitosis and took images 40-50 min after the release when we found cells at cytokinesis. Calcofluor intensity was then measured and quantified in wild-type and $c d c 55 \Delta$ cells (Fig. 1d). There was a $45 \%$ reduction in the intensity of the calcofluor staining in the absence of Cdc55 compared to control cells. Chitin is incorporated in the primary septum (PS) and secondary septa (SS); therefore, we cannot distinguish at which septum the reduction occurs. For this reason, we repeated the calcofluor staining in cells containing a deletion for $C H S 3$, the chitin synthase responsible for secondary septa formation [20]. As previously described, chs $3 \Delta$ cells showed wider bud necks and cytokinetic defects provoking the formation of chains of cells [58]. A reduction of $70 \%$ in the calcofluor intensity was measured in the chs $3 \Delta$ background in the absence of Cdc55 (Fig. 1e). Interestingly, we noticed that $82 \%(N=22)$ of the cells showed asymmetric Myo1 contraction in chs $3 \Delta$ cells (Fig. 1c), indicating defects in cytokinesis [26]. The above results indicate that primary and secondary septa formation are reduced in cells lacking PP2A-Cdc55 activity, suggesting that PP2A-Cdc55 has a role regulating septum formation.

Primary septum formation and membrane invagination occur concomitantly. To determine whether ingression of the plasma membrane could occur in $c d c 55 \Delta$ cells, we performed time-lapse video microscopy of cells expressing the small G-protein Ras2 fused to 3 copies of GFP to study plasma membrane dynamics. The visualization of the plasma membrane at the site of division revealed no cytoplasm connection between mother and daughter cells after cytokinesis, confirming that cytoplasmic division is resolved in control and $c d c 55 \Delta$ cells (Fig. S4). In conclusion, $c d c 55 \Delta$ cells have an asymmetric AMR contraction and a reduction 

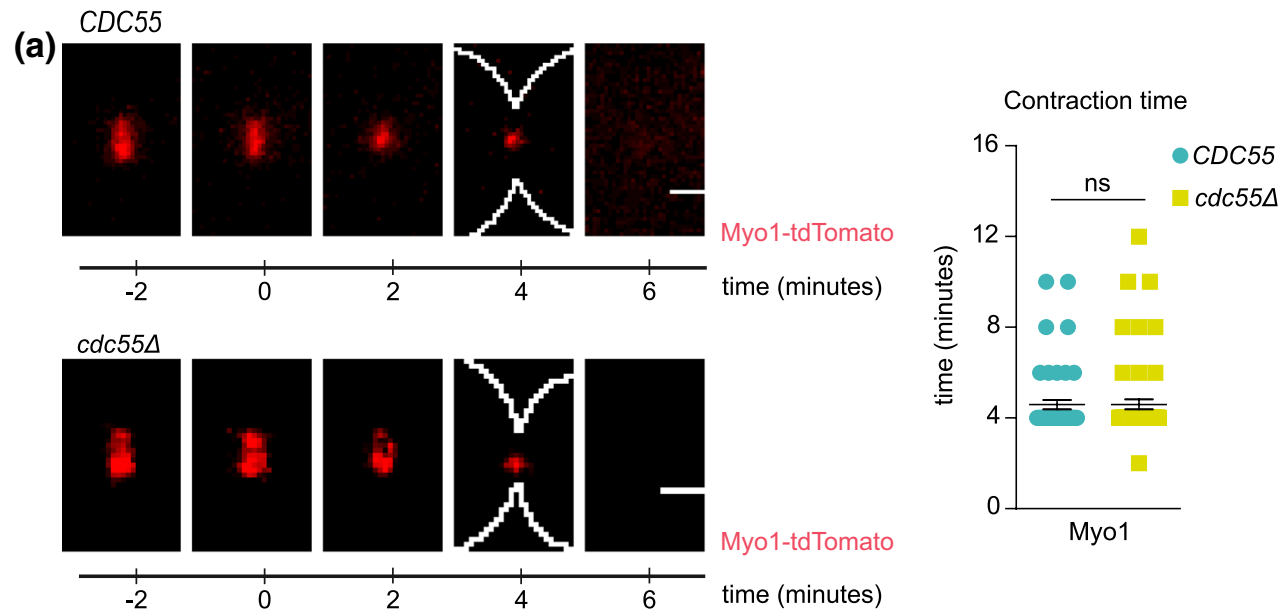

(b) Asymmetric Myo1 dot

(c) Asymmetric Myo1 dot

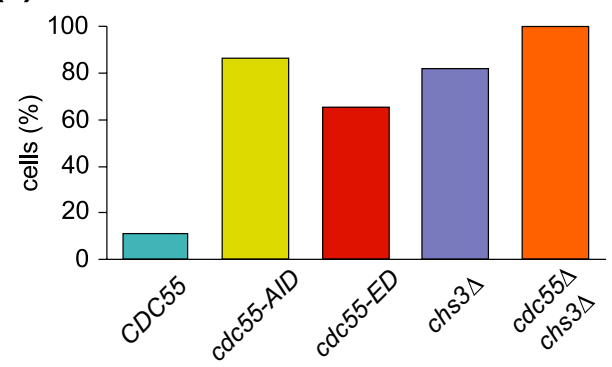

Myo1-tdTomato
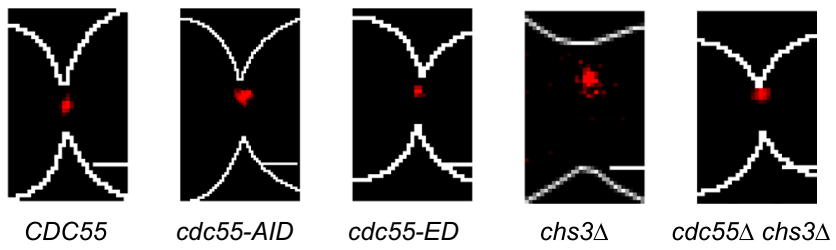

(d)

Calcofluor intensity

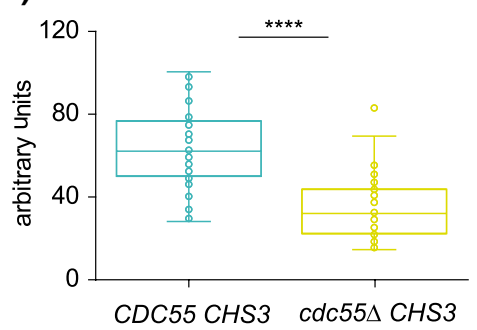

Fig. 1 PP2A-Cdc55 regulates AMR constriction and septum formation. a Absence of Cdc55 promotes the asymmetry of Myolupon AMR contraction. Strains Y1306 and Y1578 were arrested in metaphase and released into anaphase by $\mathrm{Cdc} 20$ depletion and re-addition, and time-lapse images were captured every $2 \mathrm{~min}$. Spc42-GFP (spindle pole body protein) was used as the control for anaphase progression. Representative images of Myo1 in CDC55 and $c d c 55 \Delta$ are shown (left panel). Quantification of the contraction time of Myo1 is depicted (right panel). (b) Quantification of the population of cells with asymmetric Myo1 constriction in $C D C 55(N=76)$ and $c d c 55 \Delta(N=69)$ from (a). (c) Myo1 asymmetric localization upon degradation or inactivation of Cdc55. Strains Y1652 $(N=9)$, Y1653 $(N=17), \mathrm{Y} 1788(N=35), \mathrm{Y} 1605(N=22)$ and Y1596 $(N=24)$ were

in septa formation, but nevertheless manage to complete cell division.

Next, to study the defects in septa formation we investigated the cytokinetic structure by transmission electron microscopy (TEM). We synchronized cells at the metaphaseanaphase transition by $\mathrm{Cdc} 20$ depletion and captured images
40-50 min after the synchronous release. Cells synthesizing the primary septum were identified and the structure of the septum was then examined. In wild-type cells, we observed PS formation from the cell wall following membrane invagination (Fig. 2a), as expected. Once the PS was finished, the two SS were formed on both sides of the PS 
Fig. 2 Asymmetric primary septum formation and appearance of the remedial-like septum in the absence of Cdc55. Strains Y1315, Y1318, Y1605, and $\mathrm{Y} 1596$ were arrested in metaphase and released into anaphase by $\mathrm{Cdc} 20$ depletion and re-addition. Representative images from TEM are shown. Scale bar, $0.5 \mu \mathrm{m}$. PS, SS and RS denote primary septum, secondary septa and remedial septum, respectively
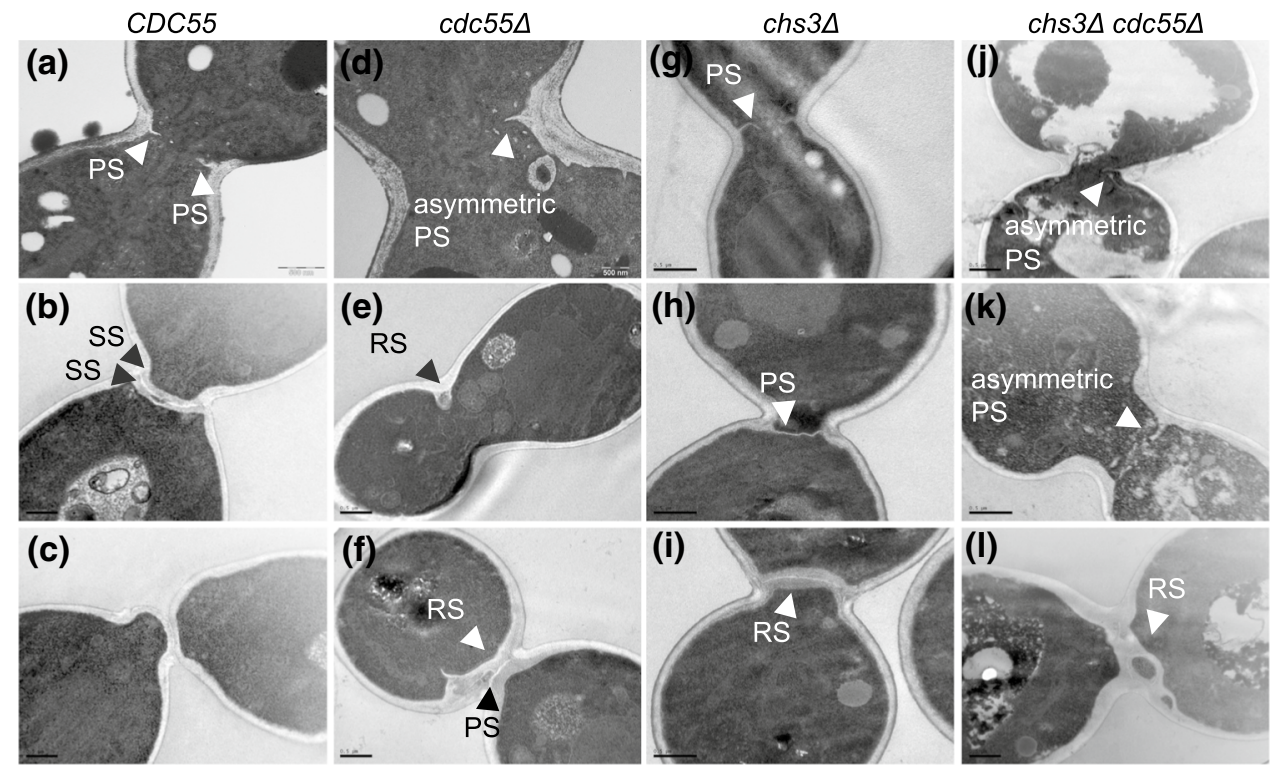

(Fig. 2b). Finally, the PS is degraded, and the cells physically separated (Fig. 2c). Conversely, in $c d c 55 \Delta$ cells, the PS emerged from only one side of the division site (Fig. 2d). From the cells performing primary septum formation, we quantified $85 \%(N=25)$ with asymmetric PS in absence of Cdc55. Some cells showed aberrant, thicker structures with diverse morphologies that resemble the secondary septa-like structures commonly referred as remedial septum (Fig. 2e). The remedial septum was first described in IPCs mutant cells, i.e., myol $\Delta$, chs $2 \Delta$ and $c h s 3 \Delta$ cells [24]. They are chitin structures reminiscent of SS that allow cells to complete cytokinesis when the PS is defective [24, 59]. Strikingly, in $c d c 55 \Delta$ cells, the mother and daughter cells are finally able to separate physically, probably upon formation of the remedial-like septum. To further investigate this hypothesis, we repeated the experiments using a chs $3 \Delta$ background in which no secondary septa is formed (Fig. 2g-i). Similar results were obtained, whence the $c d c 55 \Delta$ chs $3 \Delta$ cells had asymmetric PS formation and a remedial-like septum was formed (Fig. 2j-1). These results suggest that remedial-like septum formation enables cytoplasm separation and cell division in the absence of Cdc55.

Since AMR constriction and septum formation are simultaneous events, the asymmetric PS formation detected by EM is likely to promote the asymmetric AMR contraction observed in $c d c 55 \Delta$ cells or vice versa. In summary, our results showed that $\mathrm{PP} 2 \mathrm{~A}-\mathrm{Cdc} 55$ has a role in regulating AMR contraction and PS formation.

\section{PP2A-Cdc55 regulates the dephosphorylation of Chs2}

The Ingression Progression Complexes (IPCs) coordinate AMR constriction, plasma membrane ingression and septum formation $[17,18]$. We envisaged that PP2A-Cdc55 may have a role during cytokinesis through the dephosphorylation of IPCs proteins[60]. We initially investigated the genetic interactions between $c d c 55 \Delta$ and IPCs mutants. We prepared double mutants with $c d c 55 \Delta$ and degron-conditional mutants to induce protein degradation for the IPCs subunits[17, 61]. No differences in cell growth were observed on control plates (Fig. 3a). However, the viability of the double mutants

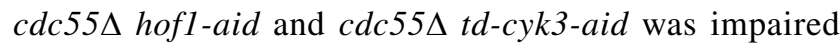
under restrictive conditions (presence of auxin) (Fig. 3a). The synthetic sick interactions found between $c d c 55 \Delta$ and hofl-aid or td-cyk3-aid degron mutants indicate that Cdc55 is functionally related to the IPC subunits, suggesting that Cdc55 is involved in the regulation of cytokinesis.

To determine whether the IPCs proteins physically interact with PP2A-Cdc55, we performed co-immunoprecipitation experiments between $\mathrm{Cdc} 55$ and Chs2. We synchronized cells in metaphase as described above, and co-purification of Chs 2 during anaphase and cytokinesis were detected in Cdc55 immunoprecipitates (Fig. 3b). Taken together, these results suggest that Chs2 forms a complex with PP2A-Cdc55 during progression through mitosis and cytokinesis.

To study the functional link between $\mathrm{Cdc55}$ and the IPCs, we studied whether PP2A-Cdc55 regulates the dephosphorylation of IPC proteins. We analyzed the phosphorylation status of the IPC proteins in the absence of Cdc55 (Fig. 3c and S5a-d) and observed an increase of Chs 2 phosphorylation levels during cytokinesis. First, we synchronized cells at metaphase and released them synchronously into anaphase to visualize the phosphorylation of Chs 2 during mitosis and cytokinesis. Mitotic spindle was stained by tubulin immunofluorescence and used as a marker of cell-cycle progression. Cdc14 release from the nucleolus was also determined as control of mitosis 


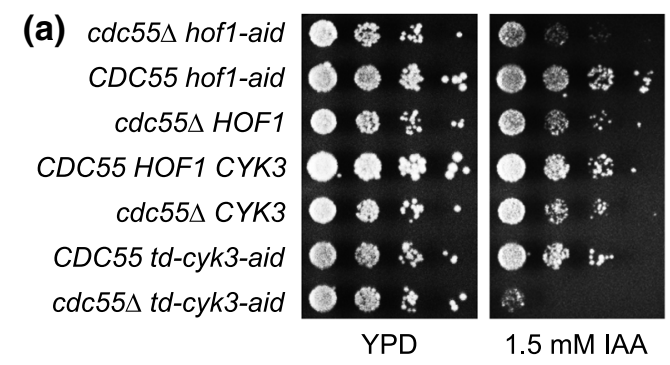

(c)

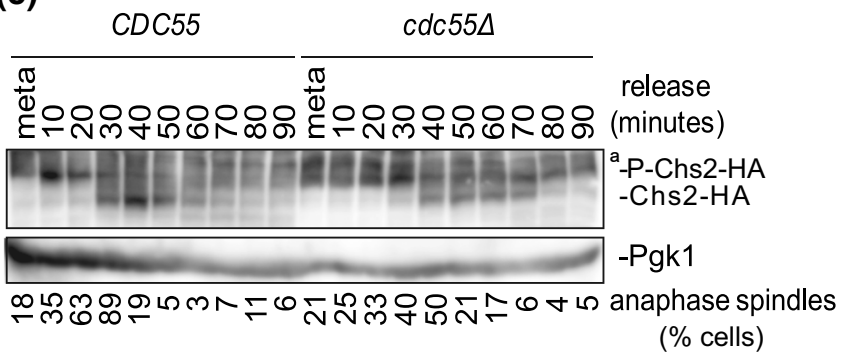

(d)

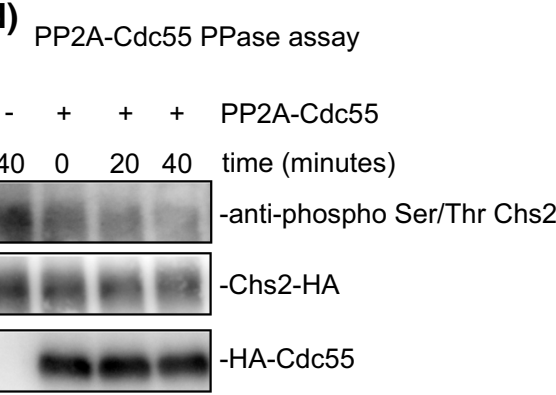

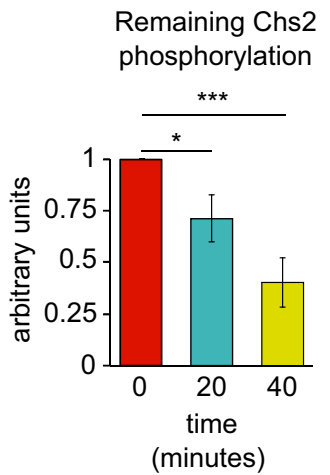

(b)

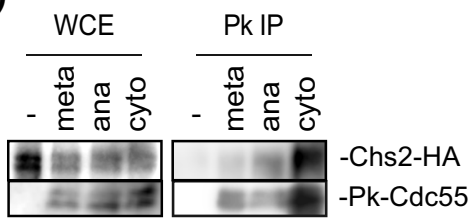

ratio phosphorylated/dephosphorylated Chs2

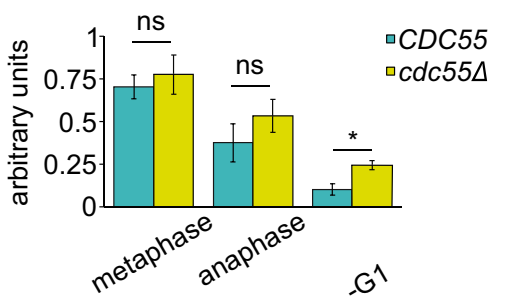

(e)

PP2A-Cdc55 PPase assay

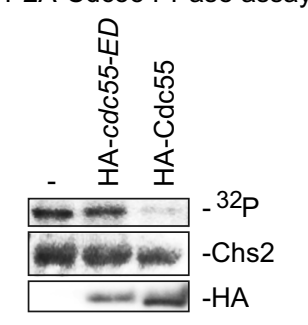

Remaining Chs2 phosphorylation

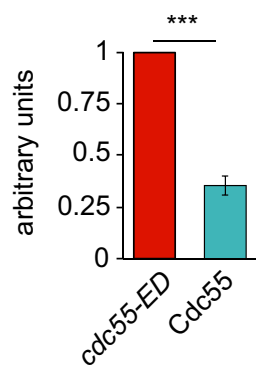

Fig. 3 PP2A-Cdc55 dephosphorylates Chs2 during cytokinesis. (a) The double mutants $c d c 55$ hofl and $c d c 55 c y k 3$ are synthetically sick. Serial dilutions ofW303, Y844, Y1728, Y1730, Y1747 and Y1749 strains were spotted on YPD plates with and without $1.5 \mathrm{mM}$ auxin (IAA). Cells were grown at $25^{\circ} \mathrm{C}$ for $2-3$ days. (b) PP2A-Cdc55 forms a complex with Chs2. Strain Y1567 was synchronized into anaphase progression by $\mathrm{Cdc} 20$ depletion and re-addition. Strain Y1318 without the Pk-tag was used as a negative control. Protein extracts were prepared at metaphase, anaphase, and cytokinesis and Cdc55 was immunoprecipitated using the anti-Pk antibody. Copurification of Chs2 was analyzed by western blot. (c) PP2A-Cdc55 regulates Chs 2 dephosphorylation. Strains Y1318 and Y1315 were arrested in metaphase and released into anaphase by Cdc20 depletion and re-addition. Chs 2 phosphorylation was analyzed by western blot in Phos-tag gels. Unspecific bands were detected for Chs2 and marked as ${ }^{(a)}$ ). Pgk1 levels were used as a loading control. Mitosis progression was followed by analyzing the anaphase spindle elongation by in situ immunofluorescence. At least 100 cells were scored at each time point. Quantification of the western blots was performed using Fiji Software and means and SEMs are represented. Student's unpaired t-test analyses were carried out using the Prism5 program. (d) Chs2 is dephosphorylated by PP2A-Cdc55. Metaphase arrested cells of the strain Y695 were used to purify the PP2A-Cdc55 complex by TAP purification. Strain Y 824 without the TAP epitope was used to prepare a Cdc55-free purification and used as a negative control. Chs2-HA was purified from metaphase arrested cells of strain Y1318. Purified Chs2-HA was incubated with or without the PP2A-Cdc55 complex at the indicated times and the Chs 2 phosphorylation levels were detected by western blot using the anti-phospho Ser/Thr antibody. Representative images of one phosphatase assay are shown. Protein levels were quantified using Fiji software. Quantifications of the remaining Chs2 phosphorylation signal normalized to the amount of Cdc55 and Chs 2 are shown. Means and SEMs of three phosphatase assays are represented. Student's unpaired t-test analysis was carried out using the Prism5 program. (e) PP2A-Cdc55 dephosphorylates Chs2 in vitro. Strains Y824, Y1652 and Y1653 were arrested in metaphase by $\mathrm{Cdc} 20$ depletion. Cdc55 and $c d c 55$ $E D$ were purified by immunoprecipitation with HA antibody. Streptag-Chs2-1-629 purified from E. coli and previously phosphorylated by $\mathrm{Cdk} 1-\mathrm{Clb} 2$ in a radioactive kinase assay was used as substrate. Representative images of the phosphatase assays are shown. Radioactive signals were detected using a multi-purpose imaging plate in a Typhoon FLA950 apparatus (GE healthcare). Protein levels were quantified using Fiji software. Quantifications of the remaining phosphorylation signals normalized with respect to the amount of immunopurified HA-Cdc55 or HA-cdc55-ED are shown. Means and SEMs of three phosphatase assays are represented. Student's unpaired $t$-test analysis was carried out using the Prism5 program 
progression. Cdc14 was prematurely released in metaphase in absence of Cdc55 as previously published[57]. During the time-course, Chs 2 protein presented slow migration isoforms at metaphase and early anaphase in control cells (Fig. 3c meta-20 min). From anaphase until early G1 (Fig. 3c; 30-50 min), two Chs 2 isoforms were detected. Since Chs 2 presented many different migrating bands, we performed an alkaline phosphatase experiment to check which corresponds to phosphorylation. In presence of alkaline phosphatase, the slower Chs 2 migrating bands collapse into the faster-migrating band indicating that the upper bands are phosphorylation events (Fig. $\mathrm{S} 5 \mathrm{e})$. Remarkably, in $c d c 55 \Delta$ mutant cells the slowermigrating isoforms are maintained throughout the timecourse, indicating that Chs2 was not efficiently dephosphorylated during late anaphase/cytokinesis (Fig. 3c; 40-70 $\mathrm{min}$ ). These results suggest that Chs 2 phosphorylation levels are altered in the absence of Cdc55 during cytokinesis.

Later, to explicitly test whether Chs2 is dephosphorylated by PP2A-Cdc55, we measured PP2A-Cdc55 phosphatase activity against Chs2 after PP2A-Cdc55 purification from metaphase-arrested cells when PP2A-Cdc55 is active [57]. Immunopurified-Chs 2 was incubated with purified PP2A-Cdc55 and Chs2 dephosphorylation was visualized using an anti-phospho Ser/Thr antibody (Fig. 3d). A Cdc55-free extract incubated with Chs2 for 40 min was used as a negative control. A $60 \%$ reduction in the Chs 2 phosphorylation signal was measured after 40 min of incubation in presence of PP2A-Cdc55. As a negative control, the phosphatase assay was done in the same conditions using separase (Esp1) as substrate. Immunopurified-Esp1 was incubated with purified PP2ACdc55 and the phosphorylation levels of Esp1 visualized with the anti-phospho Ser/Thr antibody (Fig. S5f). Esp1 phosphorylation signal was maintained during the experiment indicating that PP2A-Cdc55 is not able to dephosphorylate Esp1 in the same conditions used for Chs2. This result suggests that PP2A-Cdc55 dephosphorylation occurs specifically over Chs2.

Finally, we repeated the PP2A-Cdc55 phosphatase assay using a recombinant fragment of Chs2 (1-629) purified from E. coli and previously phosphorylated by Cdk1-Clb2. In vitro ${ }^{32} \mathrm{P}$-phosphorylated Chs2 substrate was incubated with Cdc55 immunoprecipitated from control cells expressing Cdc55 and $c d c 55-E D$ inactive version of PP2A-Cdc55 [62]. A reduction of $84 \%$ in the Chs 2 phosphorylation signal was detected in the presence of control Cdc55. The $c d c 55-E D$ mutant versions were not able to dephosphorylate Chs2 significantly (Fig. 3e). These results strongly suggest that Chs2 is dephosphorylated by PP2A-Cdc55 in vivo and in vitro.

\section{PP2A-Cdc55 regulates IPCs symmetric localization and residence time at the division site}

IPCs proteins form a complex whose function is to coordinate AMR contraction, plasma membrane ingression and PS formation $[17,18]$. For this reason, we examined whether the absence of Cdc55 disturbs the IPCs subunits proper or timely localization at the division site. To do this, we studied the localization of the IPCs subunits by time-lapse microscopy in the absence of Cdc55. We arrested cells in metaphase by $\mathrm{Cdc} 20$ depletion and captured images every 2 min after synchronous release into anaphase by Cdc20 reinduction. Iqg1, Inn 1, Hof 1, Cyk3 and Chs2 have contracted asymmetrically at the division site in $c d c 55 \Delta$ cells (Fig. 4a), consistent with the asymmetry of Myo1 described above. These findings indicate that the lack of PP2A-Cdc55 activity provokes a defective contraction of the AMR, probably as a consequence of the defective PS formation or vice versa.

We then investigated the contraction and residence time of the IPCs subunits (Fig. 4b). No differences were detected in the residence time at the bud neck in Iqg1-GFP and Inn1-GFP proteins (Fig. 4b and Fig. S6a-b). However, we observed that Hof1-GFP and Cyk3-GFP signals took longer to complete contraction and to disappear in $c d c 55 \Delta$ cells (Fig. 4b and Fig. S6c-d), further indicating that cytokinesis is affected in absence of PP2A-Cdc55. The longer localization of Hof 1 and $\mathrm{Cyk} 3$ at the division site could be a result of the impaired AMR contraction.

On the contrary, the Chs2-GFP residence time in $c d c 55 \Delta$ mutant cells was reduced compared to wild-type cells (Fig. 4b and S6e). Therefore, this result suggests that PP2A-Cdc55 regulates Chs2 localization dynamics, probably through the dephosphorylation of Chs2.

\section{Timely Chs2 dephosphorylation by PP2A-Cdc55 is required for proper AMR contraction and PS formation}

Our results suggest that PP2A-Cdc55 regulates Chs2dependent processes during cytokinesis, such as PS formation and AMR contraction, and that participates in the dephosphorylation of Chs2. Therefore, PP2A-Cdc55 might contribute to cytokinesis regulation by controlling the phosphorylation levels of Chs2.

To screen for proteins regulated by the PP2A-Cdc 55 phosphatase we studied the phosphoproteome in absence of Cdc55 by a quantitative analysis based on SILAC labeling. Phosphopeptides were enriched by Tish enrichment as described [63] and identified by LC-MS/MS. The screening revealed that a phosphopeptide corresponding to Chs2 protein was hyperphosphorylated in $c d c 55 \Delta$ mutant cells. The Chs 2 peptide contained one Cdk1 minimal S/ TP site: S133 (Fig. 5a). The phosphosite was detected 

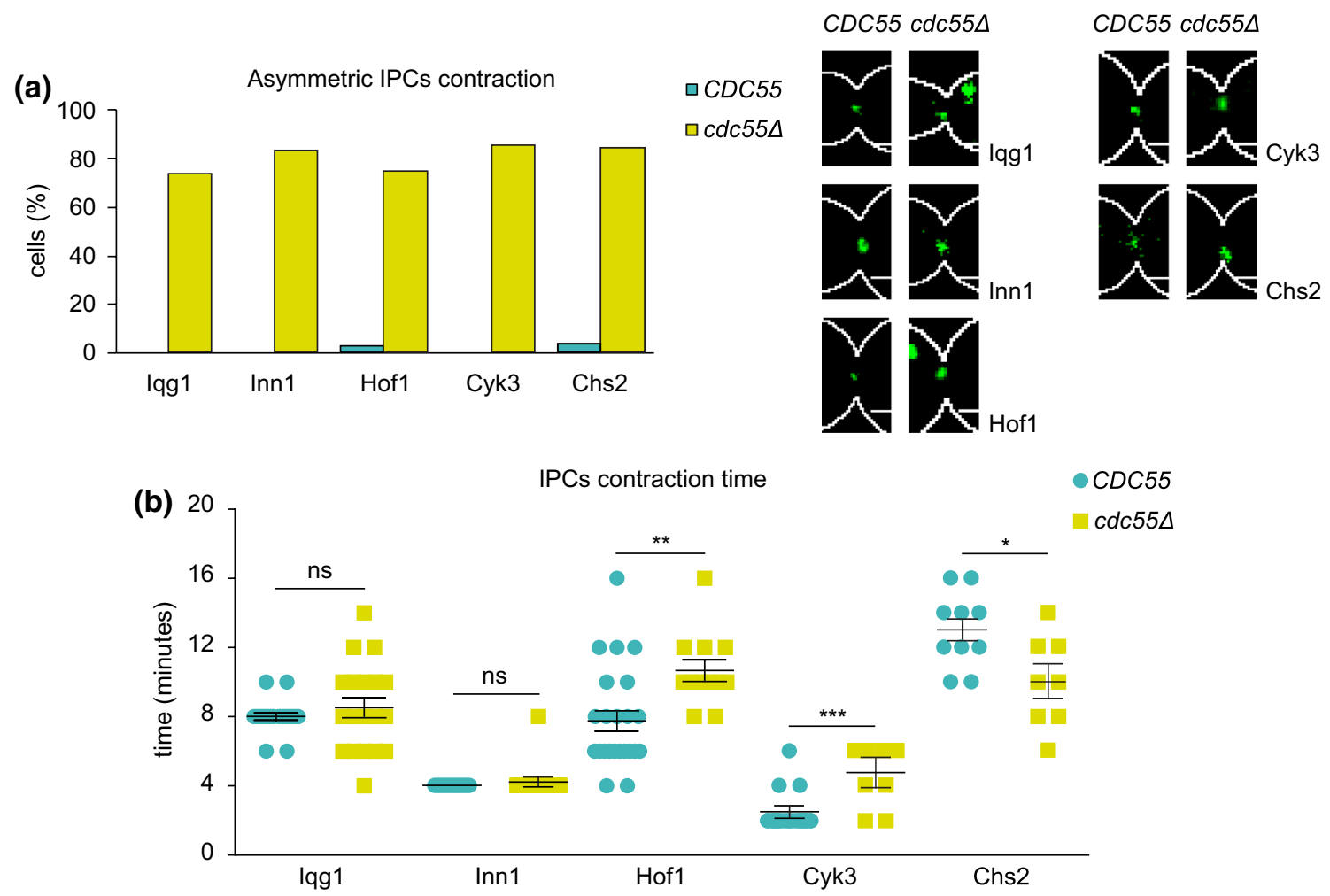

Fig. 4 PP2A-Cdc55 is required for proper IPCs localization and contraction at the division site. Strains Y1572 $(N=27)$, Y1606 $(N=28)$, Y1454 $(N=14), \mathrm{Y} 1608(N=41), \mathrm{Y} 1306(N=32), \mathrm{Y} 1578(N=12)$, Y1574 $(N=33), \mathrm{Y} 1604(N=11), \mathrm{Y} 1576(N=10)$ and $\mathrm{Y} 1575(N=8)$ were synchronized in mitosis by $\mathrm{Cdc} 20$ depletion and re-addition, and time-lapse images were captured every 2 min. Spc42-GFP and Myo1-

with the highest confidence (pRS site probability $99.9 \%$ and $p$-value $<0.00001$ ) and was also identified in a second phospho-proteomic study for $c d c 55 \Delta$ mutant cells [49]. The $\mathrm{S} 133$ is one of the $6 \mathrm{Cdk} 1$ consensus sites (S/T-P) previously reported to be phosphorylated by Cdk1 [64]. Chs2's residues S14, S60, S69 and S100 containing the SP consensus sequence were described to be efficiently dephosphorylated by $\mathrm{Cdc} 14$, and the phosphomimetic mutant at those four sites, chs $2-S 4 E$, promotes Chs 2 constitutive localization in the ER [41, 47]. Cdc14 is active as a phosphatase and prematurely released from the nucleolus in $c d c 55 \Delta$ mutant cells $[57,65]$; therefore, the $\mathrm{S} 133$ hyperphosphorylation is a consequence of the lack of PP2A-Cdc55 activity since Cdc 14 is not defective in absence of Cdc55.

To investigate whether the $\mathrm{S} 133$ is a critical Chs2 phosphorylation site, we introduced a non-phosphorylable version of Chs2, GAL1-chs2-S133A-YFP, in wild-type cells and analyzed the phosphorylation levels in Chs2-YFP immunoprecipitates using the anti-phospho Ser/Thr antibody. Chs2 phosphorylation was detected in control cells expressing the wild-type version of Chs2-YFP (Fig. 5b). By contrast, the signal was greatly reduced in the immunoprecipitation of
tdTomato were used as a control for cytokinesis progression. (a) Percentages of cells with IPCs asymmetric Myo1 contraction are shown (left panel). Representative images of GFP-tagged proteins in CDC55 and $c d c 55 \Delta$ are depicted (right panel). (b) Quantifications of the IPCs contraction times. Student's unpaired t tests were performed using the Prism5 program. Means and SEMs are represented. Scale bar, $1 \mu \mathrm{m}$

the non-phosphorylable version chs2-S133A (Fig. 5b). This result suggests that the $\mathrm{S} 133$ of Chs 2 is phosphorylated.

If the cytokinetic defects observed in $c d c 55 \Delta$ mutant cells are a consequence of the hyperphosphorylation of Chs2, the non-phosphorylable Chs2 version should rescue the asymmetric Myo1 contraction and PS formation. For this reason, we introduced the non-phosphorylable version GAL1-chs2-S133A-YFP in wild-type and cdc55 mutant strains. Cells were synchronized by $\mathrm{Cdc} 20$ depletion and re-addition and GAL1-CHS2 versions were induced prior to metaphase release. First, we followed Myo1-tdTomato and Chs2-YFP dynamics during mitosis and cytokinesis by time-lapse microscopy. Myo1 signal was asymmetric in the presence of the control Chs2-YFP ( $80 \%$ of cells; $N=25$ ), as expected in a $c d c 55 \Delta$ background (Fig. 5 c). Remarkably, in the chs2-S133A non-phosphorylable version Myo1 became symmetric in $90 \%$ of the cells $(N=31)$ (Fig. $5 \mathrm{c})$. This indicates that the non-phosphorylable Chs 2 mutant rescued the asymmetric localization of Myo1 in absence of Cdc55. Next, we wondered whether the $\operatorname{chs} 2-S 133 A$ version also rescued the longer Hof 1 contraction time observed in $c d c 55 \Delta$ cells (see Fig. 4b) by investigating the Hof1-mCherry dynamics. 
Hof 1 contraction was similar in Chs 2 and chs2-S133A in absence of Cdc55 (Fig. 5d), indicating that the delay in Hof 1 contraction in absence of Cdc55 is not due to Chs2 phosphorylation. The Hof 1 constriction times are longer, compared to Fig. 4b, presumably due to Chs 2 overexpression. Finally, we investigated the cytokinetic structure by transmission electron microscopy (TEM). Upon introduction of Chs2 and chs2-S133A in $c d c 55 \Delta$ cells, PS formation became symmetric, supporting that Chs2 activity is impaired in absence of Cdc55. Nevertheless, PS structure was aberrant (curved) in presence of the control Chs 2 and remedial septum formation was still detected (Fig. 5e). By contrast, PS structure was fully recovered and similar to WT cells upon introduction of the non-phosphorylable chs2-S133A in $c d c 55 \Delta$ cells. In conclusion, the non-phosphorylable chs 2 S133A version rescued the Myo1 asymmetric signal and the defective PS formation, suggesting that the $\mathrm{S} 133$ is the main dephosphorylated residue regulated by PP2A-Cdc55.

Finally, to investigate whether the hyperphosphorylation of Chs2 is sufficient to alter AMR symmetric contraction we introduced the phospho-mimetic chs2-S133E version in wild-type cells (Fig. 5c). No significant increase in the asymmetric Myo1 signal in the presence of $c h s 2-S 133 E$ was observed suggesting that Chs2 phosphorylation is not sufficient to promote asymmetric AMR contraction. Nevertheless, an increase in the Hof 1 residence time was observed in the phospho-mimetic chs2-S133E version compared to the control Chs 2 and chs2-S133A (Fig. 5d), similarly to what we observed in $c d c 55 \Delta$ mutant cells (compare WT and $c d c 55 \Delta$ in Fig. 4b). These results suggest that PP2A-Cdc55 has a role in cytokinesis regulating Chs 2 phosphorylation.

Overall, our findings demonstrate that the lack of PP2ACdc55 activity provokes an asymmetric contraction of the AMR and a defective PS formation that depends on the tight regulation of Chs2 phosphorylation. Therefore, Chs2 dephosphorylation by PP2A-Cdc55 is essential for maintaining proper AMR contraction and septum formation; both are required for an efficient cytokinesis.

\section{Discussion}

\section{PP2A-Cdc55 regulates Chs2 phosphorylation and its localization dynamics at the division site}

The localization and function of the IPCs subunits (Iqg1, Myo1, Hof1, Cyk3, Inn1 and Chs2 proteins), which coordinate AMR contraction, plasma membrane ingression and PS formation, are tightly regulated by phosphorylation [43, 44, 66]. To date, only two phosphatases, Cdc14 and PP2A-Rts1, are known to have a role in cytokinesis [67], and it has been described that Cdc14 dephosphorylates several subunits of the IPCs proteins such as Chs2, Inn1 and Hof 1 [39, 41, 44,
46]. A putative role for PP2A-Cdc55 in cytokinesis was also proposed because of its elongated morphology and multinucleated cells at low temperatures in $c d c 55 \Delta$ cells [68]. In addition, PP2A-Cdc55 is localized at the division site during cytokinesis [50]. However, the role of PP2A-Cdc55 during cytokinesis was not demonstrated and the molecular mechanism by which PP2A-Cdc55 regulates cytokinesis is still unknown.

Here, we describe a new function of PP2A-Cdc55 phosphatase in the regulation of cytokinesis. In summary, PP2A-Cdc55 regulates the dephosphorylation of Chs2 and it is involved in proper AMR contraction and septum formation. PP2A-Cdc55 dephosphorylates Chs 2 in vivo and in vitro, indicating that it is a PP2A-Cdc55 target. The lack of dephosphorylation of Chs 2 in absence of Cdc55 might be responsible for the defects seen in IPCs (Hof1) residence time (Fig. 4b) and AMR asymmetric contraction since the chs2-S133A (Fig. 5c, d) non-phosphorylable mutant rescues the asymmetric Myo1 signal in $c d c 55 \Delta$ mutant cells. Moreover, Chs 2 overexpression is able to rescue the asymmetric PS formation although its morphology is still impaired, further suggesting that Chs2 activity is defective in absence of Cdc55. Only the introduction of the non-phosphorylable chs2-S133A is able to rescue proper PS formation (Fig. 5e). In contrast, the phospho-mimetic mutant chs2-S133E is not sufficient to induce an asymmetric Myo1 signal in control cells, although it provokes an increase of Hof1 residence time at the division site. These results suggest that timely dephosphorylation of Chs 2 by PP2A-Cdc55 is crucial for proper AMR contraction and PS formation. Since the IPCs coordinate AMR constriction, plasma membrane ingression and septum formation, we propose that PP2A-Cdc55 is also involved in this efficient mechanism of regulation through Chs2 dephosphorylation (Fig. 6). This would explain the

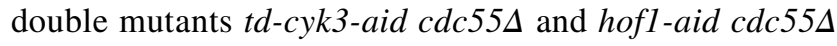
synthetic sick phenotypes, consistently with Hof1 and Cyk3 acting in parallel to activate Chs2, and in accordance with

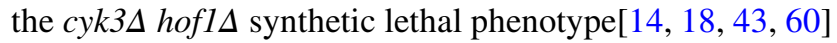

\section{The role of PP2A-Cdc55 during cytokinesis}

In the absence of Cdc55, Myo1 was constricted and unanchored in a timely fashion, but the constriction was displaced from the central axis, becoming asymmetric (Fig. 1a). This phenotype is characteristic of IPCs mutants $[6,26,52]$ and denotes a dysfunctional AMR.

On the other hand, Hof 1 asymmetric PS formation was described in chs $2 \Delta$ cells [6]; but not vice versa [6, 17], suggesting that Hof 1 also influences PS formation. Therefore, defective PS formation in absence of Cdc55 could also contribute to the asymmetry observed in the other IPCs proteins.

In addition, PP2A-Cdc55 regulates septum formation. We observed that chitin incorporation was severely reduced in 
(a)
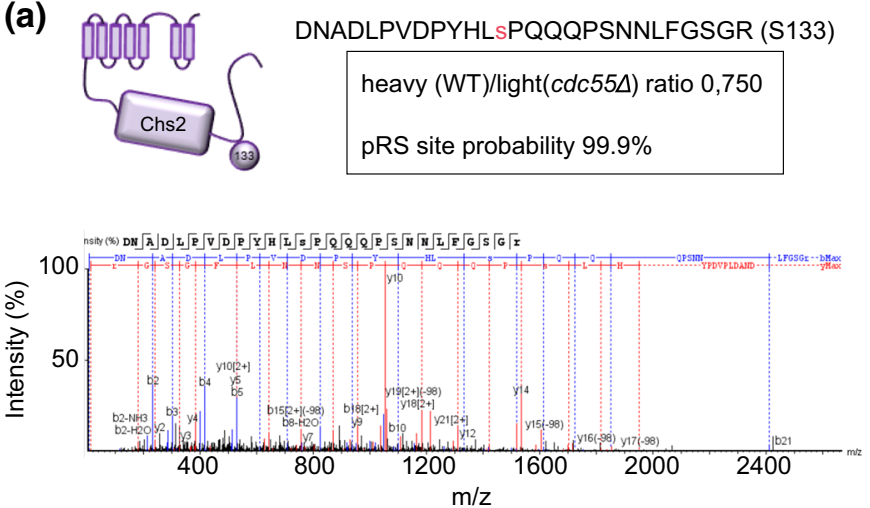

(c)

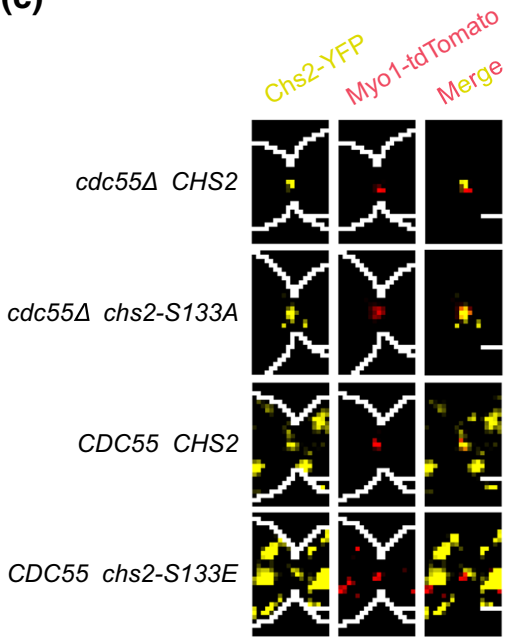

(e)

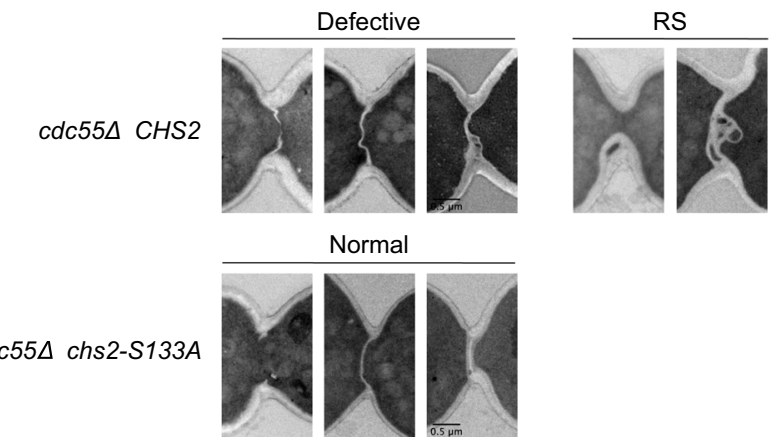

(b)

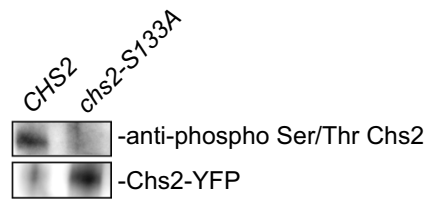

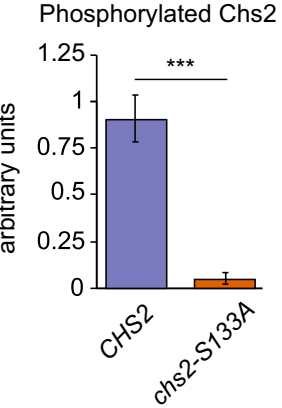

(d)
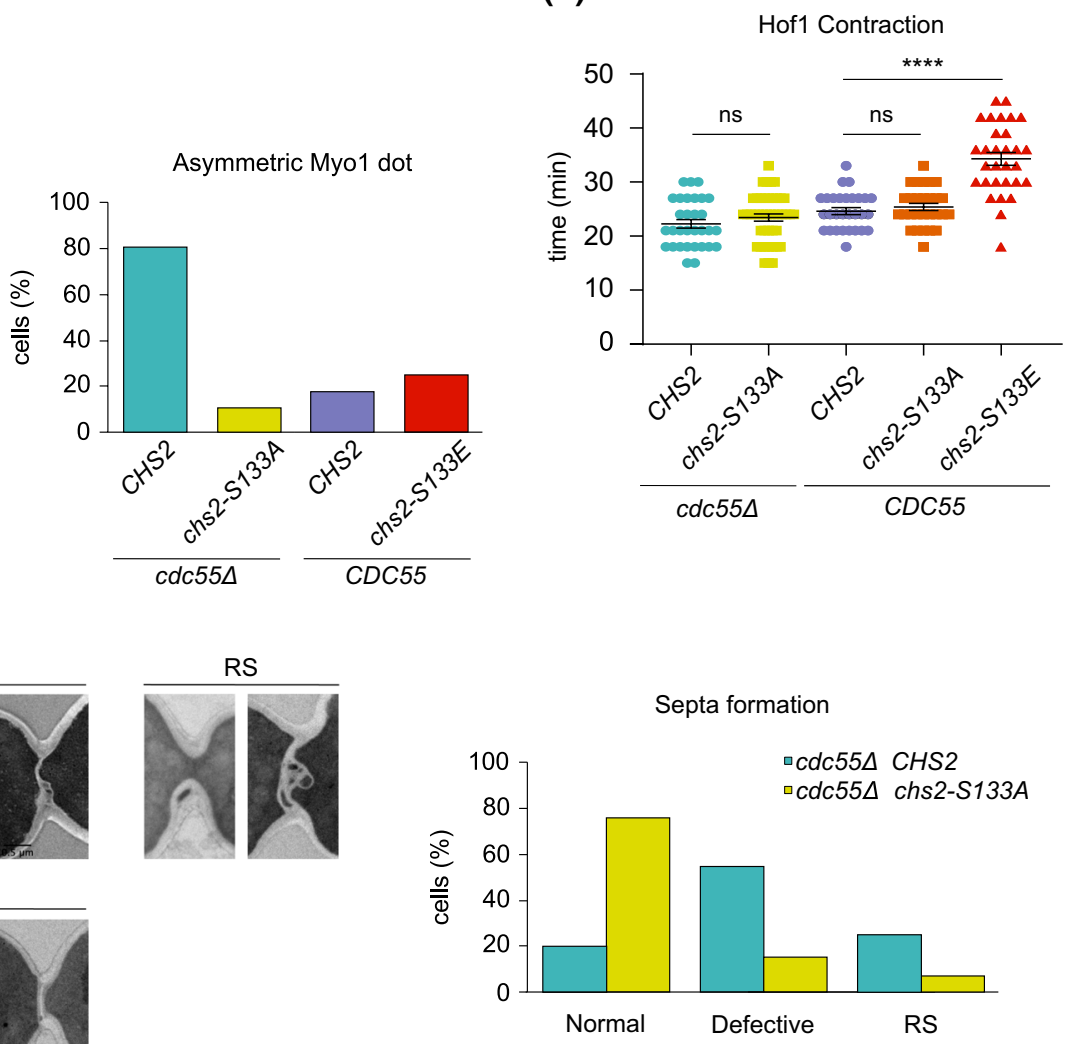

$c d c 55 \Delta$ and $c d c 55 \Delta$ chs $3 \Delta$ cells (Fig. 1d), indicating that Chs 2 activity might be impaired. Interestingly, the electron microscopy study demonstrated that the PS appears only at one side of the division site during its formation in absence of Cdc55 (Fig. 2d, j). Later, a remedial-like septum that contains even cytosol fractions embedded in the septa is detected in absence of Cdc55 (Fig. 2f, 1). The remedial septum formation was previously described in IPCs and MEN mutants with defective PS formation [13, 18, 69, 70]. Chs3 glucan synthases and mannosyltransferases are responsible for the SS formation and the construction of the remedial septum $[27,28,59]$. However, the chs $3 \Delta$ mutant is still viable and capable of dividing, suggesting that additional chitin synthases might be able to incorporate chitin in the absence of Chs3. This may explain why the remedial-like septum is still formed in the $c d c 55 \Delta$ chs $3 \Delta$ double mutant (Fig. 2i, 1).

Recently, it has been shown that multiple phosphatases shape the phospho-proteome during mitotic exit [48, 49, 71]. Notably, Hof 1 and Chs 2 phosphosites have been identified in $c d c 55$ and $c d c 14$ mutants [48]. We demonstrated that PP2ACdc55 regulates cytokinesis through the Chs2 dephosphorylation and it was reported that Cdc14-dependent dephosphorylation is required for Chs2 release from the ER [41], supporting different and specific contributions to cytokinesis of several phosphatases. We observed hyperphosphorylations of Hof 1 and Inn 1 during cytokinesis in absence of Cdc55 (Fig. S5a-b), suggesting that PP2A-Cdc55 might also regulate other IPCs proteins. Further investigations will be 
४Fig. 5 Chs2 phospho-mutants at S133 regulate AMR contraction and Hof1 residence time at the division site. (a) Hyperphosphorylation of Chs 2 in S133 was detected by mass spectrometry in absence of Cdc55. MS/MS spectrum of the Chs2 peptide containing the S133 phosphorylated from one replicate is shown. (b) Chs2 phosphorylation is greatly reduced in the chs2-S133A mutant. Strains Y1901 and Y1900 were arrested in metaphase and GAL1-CHS2 versions were induced by galactose addition for $3 \mathrm{~h}$. Protein extracts were prepared and Chs 2 and chs2-S133A purified using GFP-trap columns. Chs2 phosphorylation levels were detected by western blot using the antiphospho Ser/Thr antibody. Representative blots of one assay are shown (left panel). Western blot signals were quantified using Fiji software. Quantifications of the Chs2 phosphorylation levels normalized to the amount of Chs2 from three independent experiments are shown (right panel). Means and SEMs are represented. Student's unpaired t-test analysis was performed using the Prism5 program. (c) The non-phosphorylable $c h s 2-S 133 A$ version rescues the asymmetric AMR contraction in the $c d c 55$ mutant cells. Strains Y1896 $(N=25)$, Y1898 $(N=31), \mathrm{Y} 1895(N=35)$ and $\mathrm{Y} 1893(N=29)$ were arrested at metaphase by Cdc20 depletion. GAL1-CHS2 versions were induced by galactose addition $3 \mathrm{~h}$ before synchronous release into anaphase by $\mathrm{Cdc} 20$ re-introduction, and time-lapse images were captured every 2 min to visualize Myo1 and Chs2. Representative images of Myo1 and Chs 2 are shown (left panel). Percentages of cells with asymmetric Myo1 are represented (right panel). (d) The phosphomimetic chs $2-S 133 E$ version promotes longer Hof 1 residence time at the division site. Strains Y1912 $(N=31)$, Y1913 $(N=43)$, Y1909 $(N=29), \mathrm{Y} 1910(N=28)$ and $\mathrm{Y} 1911(N=30)$ were arrested at metaphase by Cdc20 depletion and GAL1-CHS2 versions induced as in (c). Time-lapse images were captured every $3 \mathrm{~min}$ to visualize Hof 1 and Chs2. Quantifications of the Hof 1 contraction times are represented. Student's unpaired t-tests were performed using the Prism5 program. Means and SEMs are represented. (e) The non-phosphorylable chs2-S133A version rescues the defective PS formation in the $c d c 55$ mutant cells. Strains Y1896 $(N=20)$ and Y1898 $(N=13)$ were arrested at metaphase by Cdc20 depletion and GAL1-CHS2 versions induced as in (c). Representative images from TEM are shown. Scale bar, $0.5 \mu \mathrm{m}$. Percentage of cells with normal, defective PS and with RS formation are represented. PS, SS and RS denote primary septum, secondary septa and remedial septum, respectively

required to understand the coordinated regulation of multiple phosphatases during the cell cycle.

The PP2A-Cdc55 homologue in fission yeast, PP2A-Pab1 was described to be involved in sporulation, cell wall synthesis and cytokinesis [72] suggesting that the PP2A-Cdc55 role during cytokinesis might be evolutionarily conserved. Studying the role of PP2A in model organisms will help extend our knowledge of cytokinesis in mammalian cells.

\section{Materials and methods}

\section{Yeast strains, plasmids and cell-cycle synchronization procedures}

All yeast strains used in this study were derivatives of W303 and are listed in Table S1. Epitope tagging of endogenous genes and gene deletions were performed by gene targeting using polymerase chain reaction (PCR) products [73].
Cell synchronization using $\alpha$-factor and metaphase arrest by $\mathrm{Cdc} 20$ depletion and entry into synchronous anaphase by $\mathrm{Cdc} 20$ re-introduction was performed as previously described [74]. To obtain the pGAL-CHS2-S133A-YFP construct, the S133A mutation was introduced by DNA assembly using the $p G A L 1-C H S 2-Y F P$ backbone [47].

All the $c d c 55 \Delta$ mutant strains were freshly prepared by transformation or by crossing strains to avoid the accumulation of suppressor mutations. The introduction of the $c d c 55 \Delta$ deletion was determined by PCR-genotyping and observation of the slow growth and elongated morphology under the microscope.

\section{Recombinant protein purification}

All plasmids were freshly introduced into BL21 E. coli. Cells were grown in LB medium and protein expression was induced with $0.1 \mathrm{mM}$ isopropyl $\beta$-D-1-thiogalactopyranoside (IPTG) at $25^{\circ} \mathrm{C}$ overnight. Collected cells were washed with PBS1 and frozen for at least $30 \mathrm{~min}$.

Cells containing $\mathrm{His}_{6}$-Cyk3, $\mathrm{His}_{6}-\mathrm{Inn} 1$ or $\mathrm{His}_{6}$-Hof 1 plasmids [17] were resuspended in cold lysis buffer $(30 \mathrm{mM}$ Tris- $\mathrm{HCl}, \mathrm{pH} 8,300 \mathrm{mM} \mathrm{NaCl}, 30 \mathrm{mM}$ imidazole, $0.1 \%$ NP40, $10 \mathrm{mM} \beta$-mercaptoethanol, $1 \mathrm{mM}$ PMSF, complete EDTA-free tablet (Roche)) and sonicated for 6 cycles of $1 \mathrm{~min}$ at $25 \mu \mathrm{m}$ amplitude. Protein extracts were clarified and incubated with Ni-NTA magnetic beads (Thermo Fisher) at $4^{\circ} \mathrm{C}$ for $1 \mathrm{~h}$. Beads were washed with 10 volumes of lysis buffer and protein eluted in PBS, $5 \mathrm{mM}$ EDTA, $5 \mathrm{mM}$ DTT, $0.1 \% \mathrm{NP} 40,500 \mathrm{mM}$ imidazole at $4^{\circ} \mathrm{C}$ for $30-60 \mathrm{~min}$.

Cells containing StreptagIII-Chs2_1-629 plasmid [17] were resuspended in cold lysis buffer $(50 \mathrm{mM}$ Tris- $\mathrm{HCl}$, pH 8.0, $10 \%$ glycerol, $0.1 \%$ NP-40, $10 \mathrm{mM} \mathrm{MgCl}_{2}, 300 \mathrm{mM}$ $\mathrm{NaCl}, 5 \mathrm{mM} \beta$-mercaptoethanol, 10\% BugBuster® (Millipore), $1 \mathrm{mM}$ PMSF, complete EDTA-free tablet (Roche)) containing $5 \mathrm{U} / \mathrm{mL}$ of nuclease (Pierce), incubated in a rotatory wheel at $25^{\circ} \mathrm{C}$ for $20 \mathrm{~min}$. Protein extracts were clarified and incubated with Strep-tactin ${ }^{\circledR}$ Superflow ${ }^{\circledR}$ resin (Iba Life science) at $4^{\circ} \mathrm{C}$ for $1 \mathrm{~h}$. Beads were washed with ten volumes of lysis buffer (without BugBuster()), and protein was eluted in $50 \mathrm{mM}$ Tris- $\mathrm{HCl}, \mathrm{pH} 8.0,10 \%$ glycerol, $0.1 \%$ NP-40, $10 \mathrm{mM} \mathrm{MgCl}_{2}, 150 \mathrm{mM} \mathrm{NaCl}, 5 \mathrm{mM} \beta$-mercaptoethanol, $2.5 \mathrm{mM}$ desthiobiotin at $4^{\circ} \mathrm{C}$ for $1 \mathrm{~h}$.

\section{Co-immunoprecipitation, kinase assays and phosphatase assays}

Co-immunoprecipitation assays were performed using $10^{8}$ yeast cells, which were resuspended in lysis buffer (50 mM HEPES-KOH pH 7.5, $70 \mathrm{mM}$ KOAc, $5 \mathrm{mM} \mathrm{Mg}(\mathrm{OAc})_{2}, 10 \%$ glycerol, $0.1 \%$ Triton X-100, $8 \mu \mathrm{g} /$ $\mathrm{mL}$ of protease inhibitors (leupeptin, pepstatin, aprotinin), $1 \mathrm{mM}$ PMSF, $1.25 \mathrm{mg} / \mathrm{ml}$ of benzamidin, 1 tablet 


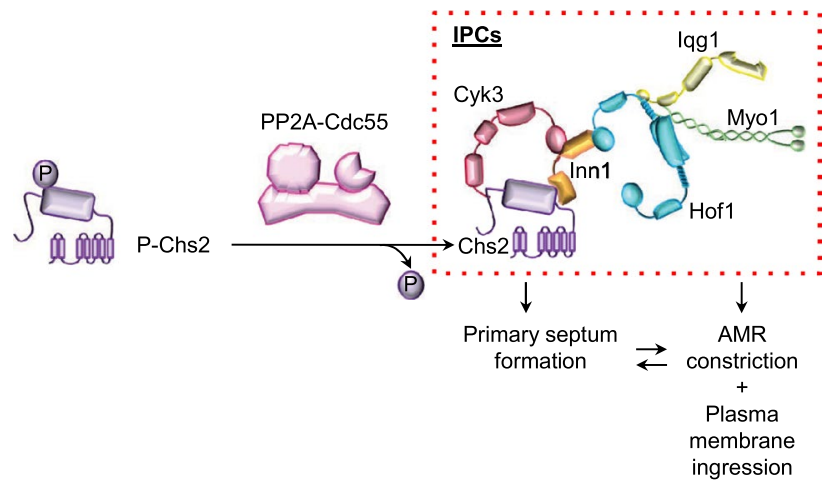

Fig. 6 Model for PP2A-Cdc55 regulation of actomyosin ring (AMR) contraction, primary septum (PS) and secondary septa (SS) formation. Dephosphorylation of Chs2 by PP2A-Cdc55 regulates AMR contraction and primary septum formation resulting in an increased Hof 1 residence time at the division site

of complete protease inhibitor without EDTA (Roche), $4 \mathrm{mM}$ of phosphatase inhibitors ( $\beta$-glycerophosphate, $\mathrm{NaF}$ and NEM) and 1 tablet of PhosStop (Roche)). Lysates were obtained by mechanical lysis using glass beads in a Bertin disrupter (6 cycles of $10 \mathrm{~s}$ at 5,000 rpm). Protein extracts were clarified by centrifugation and incubated with $\alpha$-Pk clone SV5-Pk1 (AbSerotec) or $\alpha$-HA clone 12CA5 (Roche) antibodies for $1 \mathrm{~h}$. Protein extracts were then incubated for $1 \mathrm{~h}$ with protein A-conjugated Dynabeads (Life Technologies), after which the beads were washed with lysis buffer at incremental KOAc concentrations $(100 \mathrm{mM}, 120 \mathrm{mM}$, $150 \mathrm{mM}$, and $60 \mathrm{mM} \mathrm{NaOAc}$ ). Co-immunoprecipitated proteins were eluted with loading buffer and protein copurification was visualized by western blot.

For the Chs2 alkaline phosphatase assay, metaphase arrested cells were collected and native protein extracts were prepared following the immunoprecipitation protocol. The protein extracts were incubated with alkaline phosphatase (Anthartic phosphatase, New England Biolabs) in EBX reaction buffer $(50 \mathrm{mM}$ HEPES/KOH pH 7.5, $100 \mathrm{mM} \mathrm{KCl}$, $2.5 \mathrm{mM} \mathrm{MgCl} 2,0.25 \%$ Triton X-100, 1 M DTT with protease inhibitors ( $8 \mu \mathrm{g} / \mathrm{mL}$ (leupeptin, pepstatin, aprotinin)), $1 \mathrm{mM}$ PMSF, $1.25 \mathrm{mg} / \mathrm{ml}$ of benzamidin, 1 tablet of complete protease inhibitor without EDTA (Roche)) at $37^{\circ} \mathrm{C}$ for $15 \mathrm{~min}$. To inhibit the alkaline phosphatase 2XPhosStop (Roche) was used.

To purify the PP2A-Cdc55 complex, a strain with the tandem affinity protein (TAP) epitope, TAP-HA-Cdc55 was used. A Cdc55-free pull-down was prepared using a strain without the TAP-HA epitope tagged for Cdc55 and used as a negative control. Cells from $2 \mathrm{~L}$ cultures were arrested in metaphase by $\mathrm{Cdc} 20$ depletion, frozen in liquid nitrogen and stored at $-80^{\circ} \mathrm{C}$. Cells were resuspended in lysis buffer $\left(0.1 \mathrm{M} \mathrm{NaCl}, 50 \mathrm{mM}\right.$ Tris- $\mathrm{HCl} \mathrm{pH} 7.5,1.5 \mathrm{mM} \mathrm{MgCl}_{2}$ and $0.15 \% \mathrm{NP}-40,8 \mu \mathrm{g} / \mathrm{mL}$ of protease inhibitors (leupeptin, pepstatin, aprotinin), $1 \mathrm{mM}$ PMSF, $1.25 \mathrm{mg} / \mathrm{ml}$ of benzamidin, 1 tablet of complete protease inhibitor without EDTA (Roche)) and protein extracts prepared by mechanical lysis. Protein extracts were clarified by centrifugation at $20.000 \mathrm{~g}$ and incubated with $0.4 \mathrm{~mL}$ IgG-Sepharose beads for $1 \mathrm{~h}$. The beads were extensively washed and incubated with 3 $\mu \mathrm{L}$ of TEV protease at $16^{\circ} \mathrm{C}$ for $2 \mathrm{~h}$ to remove the CBP-HA$\mathrm{Cdc} 55$ from the beads. The purified PP2A-Cdc55 was stored at $-80^{\circ} \mathrm{C}$ and used for the phosphatase assays in Fig. $3 \mathrm{~d}$ and Fig. S5f.

The Chs2-HA and Esp1-HA were purified following the co-immunoprecipitation protocol as above but using Pierce HA-magnetic beads and eluted from the beads using $1 \mathrm{mg} /$ $\mathrm{mL}$ of HA peptide. For the phosphatase assays with purified PP2A-Cdc55, eluted Chs2 or Esp1 were incubated with phosphatase reaction buffer $(50 \mathrm{mM}$ Tris- $\mathrm{HCl} \mathrm{pH7.4,}$ $0.1 \mathrm{mM}$ EGTA, $1 \mathrm{mM} \beta$-mercaptoethanol, $1 \mathrm{mg} / \mathrm{mL}$ BSA) and the purified CBP-HA-Cdc55 at $30^{\circ} \mathrm{C}$ for $20-40 \mathrm{~min}$. Reactions were terminated by adding SDS-PAGE loading buffer. Proteins were separated by electrophoresis, transferred to PVDF membranes and phosphorylation levels were detected with the anti-phospho Ser/Thr antibody (Cell Signaling) using the Supersignal West Atto Ultimate Sensitivity Substrate (Pierce). Anti-HA western blots were then performed to analyze and quantify the amount of Chs2, Esp1 and Cdc55. The phosphorylation levels were normalized against Cdc55 and Chs2 or Esp1. Proteins were quantified using Fiji software [75] and values of the mean and SEM were calculated.

For radioactive ${ }^{32} \mathrm{P}$ kinase assays, Clb2-Pk immunoprecipitations were performed as above and incubated with $\alpha-\mathrm{Pk}$ clone SV5-Pk1 (AbSerotec) antibody. Beads were washed with ten volumes of lysis buffer and twice with the kinase reaction buffer (50 mM Tris- $\mathrm{HCl}, \mathrm{pH} 7.4,10 \mathrm{mM} \mathrm{MgCl}{ }_{2}$, $1 \mathrm{mM}$ DTT). The kinase reaction (50 mM Tris-HCl, $\mathrm{pH} 7.4$, $10 \mathrm{mM} \mathrm{MgCl} 2,1 \mathrm{mM}$ DTT, $5 \mathrm{mM} \beta$-glycerophosphate, $25 \mu \mathrm{M}$ ATP, $10 \mathrm{mCi} / \mathrm{mL}^{32}$ gamma-ATP and $1 \mu \mathrm{g}$ of StreptagChs2) was incubated at $30^{\circ} \mathrm{C}$ for $30 \mathrm{~min}$. Kinase assays were stopped by placing the tubes on ice. The supernatant containing the phosphorylated substrate was separated from the magnetic beads and stored at $-80^{\circ} \mathrm{C}$. An aliquot of the kinase assay was mixed with SDS-PAGE loading buffer, proteins were separated by electrophoresis, transferred to nitrocellulose membranes and radioactivity detected in a Typhoon FLA950 (GE Healthcare). Immunopurified protein was quantified by western blot and the membrane was stained with Coomassie to detect the recombinant substrate. Proteins were quantified using Fiji software.

For in vitro phosphatase assays, cells containing $\mathrm{HA}_{3}-C d c 55-E D$ and $\mathrm{HA}_{3}-\mathrm{Cdc} 55$ were collected from metaphase arrested cells. Immunoprecipitation was performed as above but without phosphatase inhibitors. Beads were washed twice with phosphatase buffer and incubated with 
the phosphatase reaction $(50 \mathrm{mM}$ Tris- $\mathrm{HCl} \mathrm{pH} 7.4,0.1 \mathrm{mM}$ EGTA, $1 \mathrm{mM} \beta$-mercaptoethanol, $1 \mathrm{mg} / \mathrm{mL}$ BSA and the ${ }^{32} \mathrm{P}$-Streptag-Chs2) at $30^{\circ} \mathrm{C}$ for $40 \mathrm{~min}$. Reactions were terminated by adding SDS-PAGE loading buffer. Proteins were separated by electrophoresis, transferred to nitrocellulose membranes and radioactivity was detected in a Typhoon FLA950 apparatus (GE Healthcare). Later, the membrane was used to analyze and quantify the amount of protein immunoprecipitated by western blot. Finally, the membrane was stained with Coomassie to detect the recombinant Chs2 substrate. Proteins levels were quantified using Fiji software and values of the mean and SEM were calculated.

The GAL1-YFP-Chs2 and GAL1-YFP-Chs2-S133A were purified following the co-immunoprecipitation protocol as above but using GFP-Trap beads (Chromotek). Proteins were separated by electrophoresis, transferred to PVDF membranes and phosphorylation levels were detected with the anti-phospho Ser/Thr antibody (Cell Signaling) using the Supersignal West Atto Ultimate Sensitivity Substrate (Pierce). Anti-GFP western blots were then performed to analyze and quantify the amount of Chs2. The phosphorylation levels were normalized against total Chs2. Protein levels were quantified using Fiji software and values of the mean and SEM calculated.

\section{Microscopy techniques}

Synchronized cells for time-lapse experiments were deposited in chambers (Nunc Lab-Tek) containing concanavalin A/ PBS $1 \mathrm{mg} / \mathrm{mL}$. Images were captured every $2 \mathrm{~min}$. Different Z-stacks at $0.7-\mu \mathrm{m}$ intervals were taken and projected onto a single image per channel. A Zeiss-Apotome epifluorescence microscope with an HXP 120C fluorescent lamp and a Carl Zeiss Plan-Apochromat $63 \times$ N.A 1.40 oil immersion lens were used. The filters used were Cy3, GFP, and DAPI. For the GFP-Ras2 experiments, the Apotome was disabled. For the Cyk3-GFP time-lapse experiments, a Carl Zeiss LSM880 confocal microscope, with a $63 \times$ N.A. objective was used. Images were acquired using ZEN software. For the time-lapses in Fig. 5, a Leica SP8 confocal microscope with a $63 \mathrm{X}$ objective was used. Images were acquired using LAS software and quantified and processed using Fiji software. To determine the symmetry of the IPCs proteins, the bud neck length was measured, the central point was calculated and manually established whether the central point was inside (symmetry) or outside (asymmetry) the dot signal.

Calcofluor staining was performed with calcofluor white MR2 (Fluorescent brightener 28, Sigma) in living cells. Synchronized cells were incubated with $50 \mu \mathrm{g} / \mathrm{mL}$ calcofluor upon release from the metaphase arrest. Images were acquired, quantified and processed as for time-lapse experiments.
Phalloidin staining was performed on fixed cells. Cells collected during the time-course experiments were prefixed with PBS containing 3.7\% formaldehyde and $0.1 \%$ Triton $\mathrm{X}-100$ at $25^{\circ} \mathrm{C}$ for $10 \mathrm{~min}$. Cells were then washed with PBS1 and fixed with $3.7 \%$ formaldehyde at $25^{\circ} \mathrm{C}$ for $1 \mathrm{~h}$. After fixation, cells were washed twice with PBS1 and sedimented onto a multi-well slide previously incubated with poly-L-lysine. Cells were stained with a PBS solution containing $50 \mathrm{U} / \mathrm{mL}$ rhodamine-phalloidin R415 (Life Technologies) for $2 \mathrm{~h}$. Cells were washed twice with PBS1. Mounting medium containing DAPI (Vectashield) was added, cells were covered with a coverslip and sealed with nail polish. Images were acquired, quantified and processed as for timelapse experiments.

For electron microscopy, cell samples were fixed with $0.2 \mathrm{M}$ phosphate buffer (without salts) $\mathrm{pH} 7.4$, containing $2.5 \%$ glutaraldehyde at $25^{\circ} \mathrm{C}$, for $1 \mathrm{~h}$. Cells were washed three times with phosphate buffer without glutaraldehyde and rinsed with milli-Q water and post-fixed with $1 \%$ osmium tetroxide for $2 \mathrm{~h}$. They were then dehydrated in an acetone series $(10 \%, 20 \%, 30 \%, 40 \%, 60 \%, 80 \%$, and $100 \%)$ for 15-20 min. Ultrathin sections of 60-nm thickness were obtained using a UC6 ultramicrotome (Leica Microsystems, Austria) and stained with $2 \%$ uranyl acetate and lead citrate. Sections were observed in a Jeol EM J1010 apparatus (Jeol, Japan) and images were acquired at $80 \mathrm{kV}$ with a $1 \mathrm{k} \mathrm{CCD}$ Megaview camera.

\section{SILAC labeling and phosphoproteomic analysis}

Y 859 (MATa lys2 $2:: T R P 1$, arg4 $:: H I S 3$ METCDC20::LEU2) and Y858 (as Y859, but $c d c 55 \Delta$ ) cells were grown in free-methionine minimum media containing ${ }^{13} \mathrm{C}_{6}$ lysine and -arginine (heavy, Cambridge Isotope Laboratories Inc., US) or unmodified arginine and lysine (light), respectively. Protein extracts were prepared by mechanical lysis using glass beads in presence of protein inhibitors (Complete EDTA-free, Roche) and $2 \times$ phosphatase inhibitors PhosStop (Roche). Cell lysates were mixed 1:1 and digestion with trypsin was performed. The phosphopeptides were pre-enriched using $\mathrm{TiO}_{2}$ chromatography (GL Sciences Inc) followed by SIMAC purification [63]. The mono-phosphorylated peptide fraction from the SIMAC enrichment was further subjected to a second $\mathrm{TiO}_{2}$ purification and pre-fractionated by HILIC chromatography (Hydrophilic Interaction Liquid Chromatography). The peptides were then analyzed by LC-MS/MS using a LTQ-Orbitrap Fusion Tribride mass spectrometer (Thermo Fisher Scientific). Peptide identification was performed using Proteome Discoverer v1.4.1.14 (Thermo Scientific) and search against the Swiss Prot/Uniprot Saccharomyces cerevisiae database. Peptide quantification from SILAC labels was performed with Proteome Discoverer v1.4. 


\section{Other techniques}

Protein extracts for western blots were obtained by TCA protein extraction. For the phostag gels, $10 \mu \mathrm{M}$ Phostag (Wako) 5-8\% gels containing $10 \mathrm{mM} \mathrm{MnCl}_{2}$ were used. Protein gels were washed with $1 \mathrm{mM}$ EDTA before transferring protein to remove the manganese. Proteins were quantified using Fiji software, and values of the mean and SEM were calculated. To calculate the ratio of phosphorylated/dephosphorylated Chs2, the faster migration band corresponds to the dephosphorylated Chs2 (as shown in the alkaline phosphatase experiment Fig. S5e). The slower migration band observed in metaphase is considered the phosphorylated Chs2. For each triplicate, the signals were normalized against the higher signal in the blot. To assign the cells to metaphase, anaphase and cytokinesis we took into consideration the percentage of anaphase spindles and the FACS profiles (not shown). Time-points with intermediate percentages of anaphase spindles were not used in the quantification.

Antibodies used for western blots were $\alpha$-HA clone 12CA5 (Roche), $\alpha$-myc 9E10 (Babco), $\alpha$-FLAG clone M2 (Sigma), $\alpha$-Pk clone SV5-Pk1 (AbSerotec), $\alpha$-Clb2 (y-180) sc-907 (Santa Cruz Biotechnology), $\alpha$-tubulin clone YOL1/34 (Serotec), $\alpha$-phosphoglycerate kinase (Life Technologies), $\alpha$-HA rabbit (Sigma), $\alpha$-Pgk1 (Invitrogen), and $\alpha$-Chs2 [17]. The secondary antibodies were: $\alpha$-MouseHRP (GE Healthcare), $\alpha$-Rabbit-HRP (GE Healthcare), and $\alpha$-Goat-HRP (GE Healthcare). Antibodies used for immunofluorescence were: $\alpha$-HA clone 12CA5 (Roche), $\alpha-C d c 14$ (yE-17) sc-12045 (Santa Cruz Biotechnology), $\alpha$-tubulin clone YOL1/34 (AbSerotec), and $\alpha$-Cdc11 (Santa Cruz Biotechnology). The secondary antibodies were $\mathrm{Cy} 3-$ labeled $\alpha$-mouse (GE Healthcare), fluorescein-conjugated $\alpha$-rat (Millipore), Cy3-labeled $\alpha$-goat (GE Healthcare), red TEXAS $\alpha$-rabbit (Jackson Laboratories) and $488 \alpha$-mouse (Life Technologies).

\section{Statistical analysis}

All experiments were done at least three times. Statistical analyses were performed with Prism5. Student's T-test was used to analyze the p-values of the different assays compared. A p-value $<0.05$ was considered statistically significant, $* * * * p<0.0001, * * * p<0.001, * * p<0.01 ; * p<0.05$.

Supplementary Information The online version contains supplementary material available at https://doi.org/10.1007/s00018-022-04209-1.

Acknowledgements We thank the optical microscopy unit of IDIBELL, the electron microscopy units and the proteomic services from IDIBELL and CCiT-UB for their support. The $c d c 55$-aid mutant strain was a kind gift of Adam Rudner and the GAL-CHS2-YFP containing plasmids were a kind gift of Foong May Yeong. We thank all the members of our laboratory for discussing the work and for their critical reading of the manuscript.

Author contributions YMR, DV, OVC, MF and EQ performed the experiments. YMR, ASD and EQ designed the experiments and interpreted the data. YMR and EQ wrote the manuscript. All authors read and discussed the manuscript.

Funding Open Access funding provided thanks to the CRUE-CSIC agreement with Springer Nature. We thank CERCA Program/Generalitat de Catalunya for institutional support. EQ is funded by the grants BFU2016-77975-R (co-funded by the European Regional Development Fund, ERDF, a way to build Europe) from the Spanish Ministry of Economy, Industry and Competitiveness (MINECO) and PID2019-109027GB-I00 from the Spanish Ministry of Science, Innovation and Universities (MCIU). ASD was supported by the grant PID2019-106745GB-I00 from the Spanish Spanish Ministry of Science, Innovation and Universities (co-funded by the European Regional Development Fund) and a grant from the Consejería de Universidades, Investigación, Medio Ambiente y Política Social del Gobierno de Cantabria.

Data availability All the data supporting the findings of this study are available within the paper and its supplementary information files.

\section{Declarations}

Conflict of interest The authors declare no competing interests.

Open Access This article is licensed under a Creative Commons Attribution 4.0 International License, which permits use, sharing, adaptation, distribution and reproduction in any medium or format, as long as you give appropriate credit to the original author(s) and the source, provide a link to the Creative Commons licence, and indicate if changes were made. The images or other third party material in this article are included in the article's Creative Commons licence, unless indicated otherwise in a credit line to the material. If material is not included in the article's Creative Commons licence and your intended use is not permitted by statutory regulation or exceeds the permitted use, you will need to obtain permission directly from the copyright holder. To view a copy of this licence, visit http://creativecommons.org/licenses/by/4.0/.

\section{References}

1. Fujiwara T, Bandi M, Nitta M et al (2005) Cytokinesis failure generating tetraploids promotes tumorigenesis in p53-null cells. Nature 437:1043-1047. https://doi.org/10.1038/nature04217

2. Okada S, Leda M, Hanna J et al (2013) Daughter cell identity emerges from the interplay of Cdc42, septins, and exocytosis. Dev Cell 26:148-161. https://doi.org/10.1016/j.devcel.2013.06.015

3. Schneider C, Grois J, Renz C et al (2013) Septin rings act as a template for myosin higher-order structures and inhibit redundant polarity establishment. J Cell Sci 126:3390-3400. https://doi.org/ 10.1242/jcs. 125302

4. Ong K, Wloka C, Okada S et al (2014) Architecture and dynamic remodelling of the septin cytoskeleton during the cell cycle. Nat Commun 5:5698. https://doi.org/10.1038/ncomms6698

5. Lippincott J, Li R (1998) Dual function of Cyk2, a cdc15/PSTPIP family protein, in regulating actomyosin ring dynamics and septin distribution. J Cell Biol 143:1947-1960. https://doi.org/10.1083/ jcb.143.7.1947 
6. Oh Y, Schreiter J, Nishihama R et al (2013) Targeting and functional mechanisms of the cytokinesis-related F-BAR protein Hof 1 during the cell cycle. Mol Biol Cell 24:1305-1320. https://doi.org/ 10.1091/mbc.E12-11-0804

7. Meitinger F, Palani S, Hub B, Pereira G (2013) Dual function of the NDR-kinase Dbf2 in the regulation of the F-BAR protein Hof1 during cytokinesis. Mol Biol Cell. https://doi.org/10.1091/mbc. E12-08-0608

8. Finnigan GC, Booth EA, Duvalyan A et al (2015) The carboxyterminal tails of septins Cdc11 and Shs1 recruit myosin-II binding factor Bni5 to the bud neck in Saccharomyces cerevisiae. Genetics 200:843-862. https://doi.org/10.1534/genetics.115.176503

9. Shannon KB, Li R (1999) The multiple roles of Cyk1p in the assembly and function of the actomyosin ring in budding yeast. Mol Biol Cell 10:283-296. https://doi.org/10.1091/mbc.10.2.283

10. Fang X, Luo J, Nishihama R et al (2010) Biphasic targeting and cleavage furrow ingression directed by the tail of a myosin II. J Cell Biol 191:1333-1350. https://doi.org/10.1083/jcb.201005134

11. Mendes Pinto I, Rubinstein B, Kucharavy A et al (2012) Actin depolymerization drives actomyosin ring contraction during budding yeast cytokinesis. Dev Cell 22:1247-1260. https://doi.org/ 10.1016/j.devcel.2012.04.015

12. Chew TG, Huang J, Palani S et al (2017) Actin turnover maintains actin filament homeostasis during cytokinetic ring contraction. $\mathrm{J}$ Cell Biol 216:2657-2667. https://doi.org/10.1083/jcb.201701104

13. Nishihama R, Schreiter JH, Onishi M et al (2009) Role of Inn1 and its interactions with Hof 1 and $\mathrm{Cyk} 3$ in promoting cleavage furrow and septum formation in S. cerevisiae. J Cell Biol 185:995-1012. https://doi.org/10.1083/jcb.200903125

14. Jendretzki A, Ciklic I, Rodicio R et al (2009) Cyk3 acts in actomyosin ring independent cytokinesis by recruiting Inn 1 to the yeast bud neck. Mol Genet Genomics. https://doi.org/10.1007/ s00438-009-0476-0

15. Wloka C, Vallen EA, Thé L et al (2013) Immobile myosin-II plays a scaffolding role during cytokinesis in budding yeast. J Cell Biol 200:271-286. https://doi.org/10.1083/jcb.201208030

16. Devrekanli A, Foltman M, Roncero C et al (2012) Inn1 and Cyk3 regulate chitin synthase during cytokinesis in budding yeasts. J Cell Sci 125:5453-5466. https://doi.org/10.1242/jcs.109157

17. Foltman M, Molist I, Arcones I et al (2016) Ingression progression complexes control extracellular matrix remodelling during cytokinesis in budding yeast. PLoS Genet 12:e1005864. https:// doi.org/10.1371/journal.pgen.1005864

18. Wang M, Nishihama R, Onishi M, Pringle JR (2018) Role of the Hof 1-Cyk3 interaction in cleavage-furrow ingression and primary-septum formation during yeast cytokinesis. Mol Biol Cell 29:597-609. https://doi.org/10.1091/mbc.E17-04-0227

19. Sburlati A, Cabib E (1986) Chitin synthetase 2, a presumptive participant in septum formation in Saccharomyces cerevisiae. $\mathrm{J}$ Biol Chem 261:15147-15152

20. Shaw JA, Mol PC, Bowers B et al (1991) The function of chitin synthases 2 and 3 in the Saccharomyces cerevisiae cell cycle. J Cell Biol 114:111-123. https://doi.org/10.1083/jcb.114.1.111

21. Okada H, MacTaggart B, Ohya Y, Bi E (2021) The kinetic landscape and interplay of protein networks in cytokinesis. Science 24:101917. https://doi.org/10.1016/j.isci.2020.101917

22. Foltman M, Filali-Mouncef Y, Crespo D, Sanchez-Diaz A (2018) Cell polarity protein Spa2 coordinates Chs2 incorporation at the division site in budding yeast. PLoS Genet 14:e1007299. https:// doi.org/10.1371/journal.pgen.1007299

23. Wloka C, Bi E (2012) Mechanisms of cytokinesis in budding yeast. Cytoskeleton 69:710-726. https://doi.org/10.1002/cm. 21046

24. Schmidt M, Bowers B, Varma A et al (2002) In budding yeast, contraction of the actomyosin ring and formation of the primary septum at cytokinesis depend on each other. J Cell Sci 115:293-302

25. VerPlank L, Li R (2005) Cell cycle-regulated trafficking of Chs2 controls actomyosin ring stability during cytokinesis. Mol Biol Cell 16:2529-2543. https://doi.org/10.1091/mbc.E04-12-1090

26. Sanchez-Diaz A, Marchesi V, Murray S et al (2008) Inn1 couples contraction of the actomyosin ring to membrane ingression during cytokinesis in budding yeast. Nat Cell Biol 10:395-406. https:// doi.org/10.1038/ncb1701

27. Cabib E, Sburlati A, Bowers B, Silverman SJ (1989) Chitin synthase 1, an auxiliary enzyme for chitin synthesis in Saccharomyces cerevisiae. J Cell Biol 108:1665-1672. https://doi.org/10.1083/ jcb.108.5.1665

28. Douglas CM, Foor F, Marrinan JA et al (1994) The Saccharomyces cerevisiae FKS1 (ETG1) gene encodes an integral membrane protein which is a subunit of $1,3-\beta$-D-glucan synthase. Proc Natl Acad Sci USA 91:12907-12911. https://doi.org/10. 1073/pnas.91.26.12907

29. Weiss EL (2012) Mitotic exit and separation of mother and daughter cells. Genetics 192:1165-1202. https://doi.org/10. 1534/genetics.112.145516

30. Queralt E, Uhlmann F (2008) Cdk-counteracting phosphatases unlock mitotic exit. Curr Opin Cell Biol 20:661-668. https:// doi.org/10.1016/j.ceb.2008.09.003

31. Baro B, Queralt E, Monje-Casas F (2017) Regulation of mitotic exit in Saccharomyces cerevisiae. Methods in molecular biology. Springer, pp 3-17

32. Rock JM, Amon A (2009) The FEAR network. Curr Biol 19:R1063-R1068. https://doi.org/10.1016/j.cub.2009.10.002

33. Hotz M, Barral Y (2014) The mitotic exit network: new turns on old pathways. Trends Cell Biol 24:145-152

34. Visintin R, Craig K, Hwang ES et al (1998) The phosphatase Cdc14 triggers mitotic exit by reversal of cdk-dependent phosphorylation. Mol Cell 2:709-718. https://doi.org/10.1016/ S1097-2765(00)80286-5

35. Jiménez J, Castelao BA, González-Novo A, Sánchez-Pérez M (2005) The role of MEN (mitosis exit network) proteins in the cytokinesis of Saccharomyces cerevisiae. Int Microbiol 8:33-42

36. Meitinger F, Boehm ME, Hofmann A et al (2011) Phosphorylation-dependent regulation of the F-BAR protein Hof 1 during cytokinesis. Genes Dev 25:875-888. https://doi.org/10.1101/ gad.622411

37. Yoshida S, Kono K, Lowery DM et al (2006) Polo-like kinase Cdc5 controls the local activation of Rho1 to promote cytokinesis. Science 313:108-111. https://doi.org/10.1126/science. 1126747

38. Naylor SG, Morgan DO (2014) Cdk1-dependent phosphorylation of iqg1 governs actomyosin ring assembly prior to cytokinesis. J Cell Sci 127:1128-1137. https://doi.org/10.1242/jcs. 144097

39. Miller DP, Hall H, Chaparian R et al (2015) Dephosphorylation of Iqg 1 by Cdc14 regulates cytokinesis in budding yeast. Mol Biol Cell 26:2913-2926. https://doi.org/10.1091/mbc.E14-12-1637

40. Zhang G, Kashimshetty R, Kwee EN et al (2006) Exit from mitosis triggers Chs $2 p$ transport from the endoplasmic reticulum to mother-daughter neck via the secretory pathway in budding yeast. J Cell Biol 174:207-220. https://doi.org/10.1083/jcb.200604094

41. Chin CF, Bennett AM, Ma WK et al (2012) Dependence of Chs2 ER export on dephosphorylation by cytoplasmic Cdc14 ensures that septum formation follows mitosis. Mol Biol Cell 23:45-58. https://doi.org/10.1091/mbc.E11-05-0434

42. Jakobsen MK, Cheng Z, Lam SK et al (2013) Phosphorylation of Chs2p regulates interaction with COPII. J Cell Sci 126:21512156. https://doi.org/10.1242/jcs.115915

43. Meitinger F, Petrova B, Lombardi IM et al (2010) Targeted localization of Inn1, Cyk3 and Chs2 by the mitotic-exit network 
regulates cytokinesis in budding yeast. J Cell Sci 123:1851-1861. https://doi.org/10.1242/jcs.063891

44. Palani S, Meitinger F, Boehm ME et al (2012) Cdc14-dependent dephosphorylation of Inn1 contributes to Inn1-Cyk3 complex formation. J Cell Sci 125:3091-3096. https://doi.org/10.1242/ jes. 106021

45. Sanchez-Diaz A, Nkosi PJ, Murray S et al (2012) The mitotic exit network and $\mathrm{Cdc} 14$ phosphatase initiate cytokinesis by counteracting CDK phosphorylations and blocking polarised growth. EMBO J 31:3620-3634. https://doi.org/10.1038/emboj.2012.224

46. Kuilman T, Maiolica A, Godfrey M et al (2015) Identification of Cdk targets that control cytokinesis. EMBO J 34:81-96. https:// doi.org/10.15252/embj.201488958

47. Teh EM, Chai CC, Yeong FM (2009) Retention of Chs2p in the ER requires N-terminal CDK1-phosphorylation sites. Cell cycle (Georgetown, Tex) 8:2964-2974

48. Touati SA, Hofbauer L, Jones AW et al (2019) Cdc14 and PP2A phosphatases cooperate to shape phosphoproteome dynamics during mitotic exit. Cell Rep 29:2015-2119. https://doi.org/10.1016/j. celrep.2019.10.041

49. Touati SA, Kataria M, Jones AW et al (2018) Phosphoproteome dynamics during mitotic exit in budding yeast. EMBO J 37:e98745. https://doi.org/10.15252/embj.201798745

50. Gentry MS, Hallberg RL (2002) Localization of Saccharomyces cerevisiae protein phosphatase $2 \mathrm{~A}$ subunits throughout mitotic cell cycle. Mol Biol Cell 13:3477-3492. https://doi.org/10.1091/ mbc.02-05-0065

51. Dobbelaere J, Barral Y (2004) Spatial coordination of cytokinetic events by compartmentalization of the cell cortex. Science 305:393-396. https://doi.org/10.1126/science.1099892

52. Lippincott J, Li R (1998) Sequential assembly of myosin II, an IQGAP-like protein, and filamentous actin to a ring structure involved in budding yeast cytokinesis. J Cell Biol 140:355-366. https://doi.org/10.1083/jcb.140.2.355

53. McQuilken M, Jentzsch MS, Verma A et al (2017) Analysis of septin reorganization at cytokinesis using polarized fluorescence microscopy. Front Cell Develop Biol 5:42. https://doi.org/10. 3389/fcell.2017.00042

54. Jonasson EM, Rossio V, Hatakeyama R et al (2016) Zds1/Zds2PP2A(Cdc55) complex specifies signaling output from Rho1 GTPase. J Cell Biol 212:51-61. https://doi.org/10.1083/jcb.20150 8119

55. Kennedy EK, Dysart M, Lianga N et al (2016) Redundant regulation of Cdk1 tyrosine dephosphorylation in Saccharomyces cerevisiae. Genetics 202:903-910. https://doi.org/10.1534/genetics. 115.182469

56. Minshull J, Straight A, Rudner AD et al (1996) Protein phosphatase $2 \mathrm{~A}$ regulates MPF activity and sister chromatid cohesion in budding yeast. Curr Biol 6:1609-1620. https://doi.org/10.1016/ S0960-9822(02)70784-7

57. Queralt E, Lehane C, Novak B, Uhlmann F (2006) Downregulation of PP2ACdc55 phosphatase by separase initiates mitotic exit in budding yeast. Cell 125:719-732. https://doi.org/10.1016/j.cell. 2006.03.038

58. Walker LA, Lenardon MD, Preechasuth K et al (2013) Cell wall stress induces alternative fungal cytokinesis and septation strategies. J Cell Sci 126:2668-2677. https://doi.org/10.1242/jcs. 118885

59. Cabib E, Schmidt M (2003) Chitin synthase III activity, but not the chitin ring, is required for remedial septa formation in budding yeast. FEMS Microbiol Lett 224:299-305. https://doi.org/ 10.1016/S0378-1097(03)00477-4

60. Korinek WS, Bi E, Epp JA et al (2000) Cyk3, a novel SH3-domain protein, affects cytokinesis in yeast. Curr Biol. https://doi.org/10. 1016/S0960-9822(00)00626-6
61. Nishimura K, Fukagawa T, Takisawa H et al (2009) An auxinbased degron system for the rapid depletion of proteins in nonplant cells. Nat Methods 6:917-922. https://doi.org/10.1038/ nmeth. 1401

62. Játiva S, Calabria I, Moyano-Rodriguez Y et al (2019) Cdc14 activation requires coordinated Cdk1-dependent phosphorylation of Net1 and PP2A-Cdc55 at anaphase onset. Cell Mol Life Sci 76:3601-3620. https://doi.org/10.1007/s00018-019-03086-5

63. Baro B, Játiva S, Calabria I et al (2018) SILAC-based phosphoproteomics reveals new PP2A-Cdc55-regulated processes in budding yeast. GigaScience 7:407. https://doi.org/10.1093/gigas cience/giy047

64. Holt LJ, Tuch BB, Villén J et al (2009) Global analysis of Cdk1 substrate phosphorylation sites provides insights into evolution. Science (New York, NY) 325:1682-1686. https://doi.org/10.1126/ science. 1172867

65. Baro B, Rodriguez-Rodriguez J-A, Calabria I et al (2013) Dual regulation of the mitotic exit network (MEN) by PP2A-Cdc55 phosphatase. PLoS Genet 9:e1003966. https://doi.org/10.1371/ journal.pgen.1003966

66. Vallen EA, Caviston J, Bi E (2000) Roles of Hof 1p, Bnilp, Bnr1p, and Myo1p in cytokinesis in Saccharomyces cerevisiae. Mol Biol Cell 11:593-611. https://doi.org/10.1091/mbc.11.2.593

67. Dobbelaere J, Gentry MS, Hallberg RL, Barral Y (2003) Phosphorylation-dependent regulation of septin dynamics during the cell cycle. Dev Cell 4:345-357. https://doi.org/10.1016/S15345807(03)00061-3

68. Healy AM, Zolnierowicz S, Stapleton AE et al (1991) CDC55, a Saccharomyces cerevisiae gene involved in cellular morphogenesis: identification, characterization, and homology to the $\mathrm{B}$ subunit of mammalian type $2 \mathrm{~A}$ protein phosphatase. Mol Cell Biol 11:5767-5780. https://doi.org/10.1128/mcb.11.11.5767

69. Park SY, Cable AE, Blair J et al (2009) Bub2 regulation of cytokinesis and septation in budding yeast. BMC Cell Biol 10:43. https://doi.org/10.1186/1471-2121-10-43

70. Oh Y, Chang KJ, Orlean P et al (2012) Mitotic exit kinase Dbf2 directly phosphorylates chitin synthase Chs2 to regulate cytokinesis in budding yeast. Mol Biol Cell 23:2445-2456. https://doi. org/10.1091/mbc.E12-01-0033

71. Godfrey M, Touati SA, Kataria M et al (2017) PP2A(Cdc55) phosphatase imposes ordered cell-cycle phosphorylation by opposing threonine phosphorylation. Mol Cell 65:393-402.e3. https://doi. org/10.1016/j.molcel.2016.12.018

72. Kinoshita K, Nemoto T, Nabeshima K et al (1996) The regulatory subunits of fission yeast protein phosphatase 2A (PP2A) affect cell morphogenesis, cell wall synthesis and cytokinesis. Genes Cells. https://doi.org/10.1046/j.1365-2443.1996.02002.x

73. Knop M, Siegers K, Pereira G et al (1999) Epitope tagging of yeast genes using a PCR-based strategy: More tags and improved practical routines. Yeast 15:963-972. https://doi.org/10.1002/ (SICI)1097-0061(199907)15:10B\%3c963::AID-YEA399\%3e3.0. $\mathrm{CO} ; 2-\mathrm{W}$

74. Monje-Casas F, Queralt E (2017) The mitotic exit network. Humana Press

75. Schindelin J, Arganda-Carreras I, Frise E et al (2012) Fiji: an open-source platform for biological-image analysis. Nat Methods 9:676-682. https://doi.org/10.1038/nmeth.2019

Publisher's Note Springer Nature remains neutral with regard to jurisdictional claims in published maps and institutional affiliations. 